\title{
Evidence-Based Practice in Practice Exploring Conditions for Using Research in Physiotherapy
}

Petra Dannapfel

Division of Community Medicine

Department of Medical and Health Sciences

Linköping University, Sweden

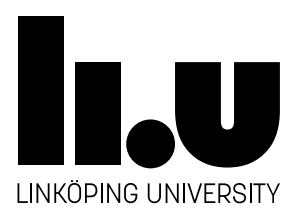

Linköping 2015 
(C) Petra Dannapfel 2015

Cover illustration: Åsa Källstrand Thor

Published article has been reprinted with the permission of the copyright holder.

Printed in Sweden by LiU-Tryck, Linköping, Sweden, 2015

ISBN 978-91-7519-019-8

ISSN 0345-0082 
Look up at the stars and not down at your feet. Try to make sense of what you see, and wonder about what makes the universe exist. Be curious.

(Stephen Hawking)

Knowledge is relative to time and place, never absolute across time and space

(Patton, 2002) 



\section{CONTENTS}

\section{CONTENTS}

\section{ABSTRACT}

\section{LIST OF PAPERS}

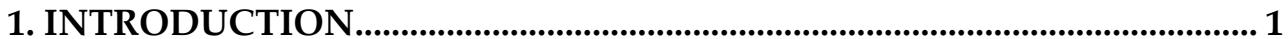

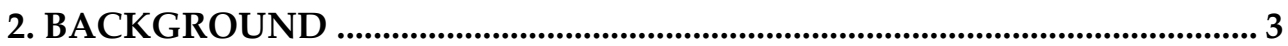

2.1. Physiotherapy ................................................................................................ 3

2.2. Evidence-based practice............................................................................... 6

2.2.1. From evidence-based medicine to evidence-based practice .......... 6

2.2.2. Conceptualising evidence-based practice ......................................... 8

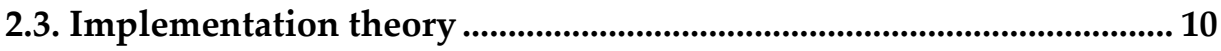

2.3.1. Origins of and influences on implementation science ................... 10

2.4. Theories used in the thesis........................................................................... 12

2.4.1. Individual-level behaviour change theories ..................................... 13

2.4.2. Individual and organizational learning theories ............................ 13

2.4.3. Organizational theories: culture and leadership............................. 15

2.5. Previous research on implementation of evidence-based practice in physiotherapy ................................................................................................ 17

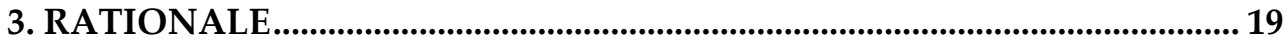

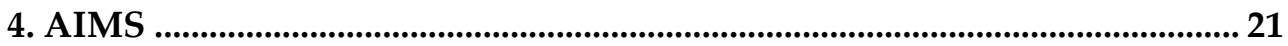

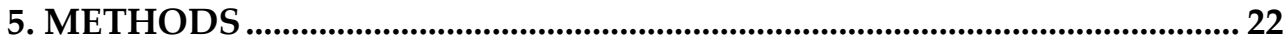

5.1. Overview of the methods ............................................................................. 22

5.2. Study setting characteristics ....................................................................... 24 
5.3. Study participants and data collection ....................................................... 24

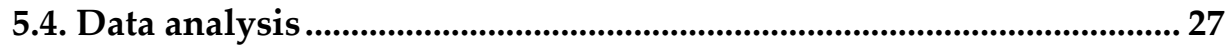

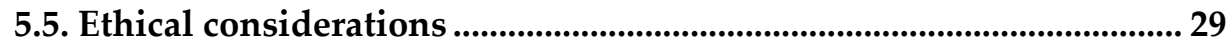

6. FINDINGS FROM THE STUDIES ………............................................................. 30



6.2. Study II......................................................................................................... 31

6.3. Study III ........................................................................................................... 33

6.4. Study IV .............................................................................................................. 34

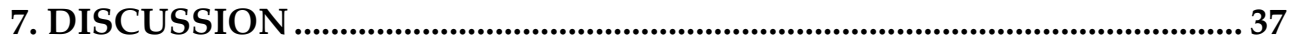

7.1. Key research findings..................................................................................... 37

7.2. A multi-level approach ............................................................................... 39

7.3. Individual-level conditions ....................................................................... 41

7.4. Contextual conditions (workplace, organizational and extraorganizational levels) .......................................................................................... 43

7.5. Putting the levels together ......................................................................... 46

7.6. Some reflections on evidence-based practice in physiotherapy ........ 47

7.7. Methodological considerations ..................................................................... 48

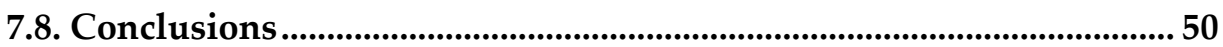

7.9. Future research ............................................................................................ 51

POSTFACE

SVENSK SAMMANFATTNING _........................................................................5 59

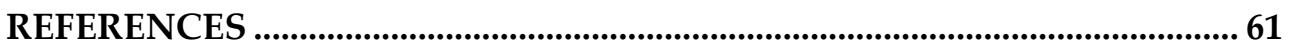

Internet sources ……............................................................................................. 78 


\section{ABSTRACT}

Research developments have led to increased opportunities for the use of improved diagnostic and treatment methods in physiotherapy and other areas of health care. The emergence of the evidence-based practice (EBP) movement has led to higher expectations for a more research-informed health care practice that integrates the best available research evidence with clinical experience and patient priorities and values. Physiotherapy research has grown exponentially, contributing to an increased interest in achieving a more evidence-based physiotherapy practice. However, implementation research has identified many individual and contextual barriers to research use. Strategies to achieve a more EBP tend to narrowly target individual practitioners to influence their knowledge, skills and attitudes concerning research use. However, there is an emerging recognition that contextual conditions such as leadership and culture are critical to successfully implementing EBP.

Against this background, the overall aim of this thesis was to explore conditions at different levels, from the individual level to the organizational level and beyond, for the use of research and implementation of an evidence-based physiotherapy practice. The thesis consists of four interrelated papers that address various aspects of the aim. Individual and focus group interviews were conducted with physiotherapists and managers within physiotherapy in various county councils in Sweden between 2011 and 2014. Data were analysed using qualitative content analysis, direct content analysis and hermeneutics.

It was found that many different types of motivation underlie physiotherapists' use of research in their clinical practice, from amotivation (i.e. a lack of intention to engage in research use) to intrinsic motivation (research use is perceived as interesting and satisfying in itself). Most physiotherapists tend to view research use in favourable terms. Physiotherapists' participation in a research project can yield many individual learning experiences that might contribute to a more research-informed physiotherapy practice. However, organizational learning was more limited. Numerous conditions at different levels (individual, workplace and extra-organizational levels) provide support for physiotherapists' use of research in their clinical practice. However, physiotherapy leaders appear to contribute to a modest degree to establishing a culture that is conducive to implementing EBP in physiotherapy practice. Instead, 
EBP issues largely seem to depend on committed individual physiotherapists who keep to up to date with research in physiotherapy and inform colleagues about the latest research findings. 


\section{LIST OF PAPERS}

Study I. Petra Dannapfel, Anneli Peolsson, Christian Ståhl, Birgitta Öberg, and Per Nilsen (2013): Applying Self-Determination Theory for improved understanding of physiotherapists' rationale for using research in clinical practice: a qualitative study in Sweden. Physiotherapy Theory and Practice, 30, 20-28

Study II. Petra Dannapfel, Anneli Peolsson, Per Nilsen (2013): What supports physiotherapists' use of research in clinical practice? A qualitative study in Sweden. Implementation Science, 8:31

Study III. Petra Dannapfel, Anneli Peolsson, Per Nilsen (2014): A qualitative study of individual and organizational learning through physiotherapists' participation in a research project. International Journal of Clinical Medicine, 5, 514524

Study IV. Petra Dannapfel, Per Nilsen (2015): Fostering a culture of evidencebased physiotherapy practice: a qualitative analysis of the influence of health care leaders. Submitted. 



\section{INTRODUCTION}

The concept of evidence-based practice (EBP) has attracted wide attention over the past two decades. EBP is often viewed as a response to growing demands in many fields that professional practice should be based on the most up-todate, valid and reliable research. The concept of EBP is typically defined as the use of evidence (i.e. research) combined with professional expertise and patient preference (Aveyard and Sharp, 2013). Hence, this tripartite definition specifies that EBP is not just about evidence; research use alone is not sufficient to "practice" EBP, as this research must be supplemented with the judgement of the practitioner and the priorities and values conveyed by the patient. However, much research attention has been devoted to the "evidence" component of EBP, i.e. issues concerning health care practitioners' use of research in their routine practice. The reason for this research interest is the recognition that "getting evidence into practice" is challenging. Implementation science has emerged as a vital field with research into influences on practice change and approaches to promote the uptake of research findings (Mittman, 2012).

This thesis concerns EBP in physiotherapy, a health care profession that has been strongly influenced by the evidence-based movement. Indeed, many influential physiotherapy representatives, including researchers, practitioners and policymakers, have argued that physiotherapists have a moral and professional obligation to abandon the use of diagnostic and treatment methods (interventions, programmes, etc.) based on opinion, anecdotal evidence of success or simply because they are experience-based habitual practice. The move towards a more evidence-based physiotherapy practice has been described as something of a "pressing issue" in physiotherapy (Iles and Davidson, 2006; page 94), which is "driven by the profession's collective need to validate its position in health care" (Taylor and Copeland, 2006; page 105).

The importance of attaining a more EBP in physiotherapy has been increasingly emphasized, but research has documented many barriers to implementing EBP in physiotherapy. These barriers are broadly similar to those in many other areas and professions in health care. With regard to physiotherapy, the sheer volume and improved accessibility of clinical physiotherapy research has make it difficult for practitioners to keep pace with all the latest research advances, and to integrate new findings into their everyday practice. At the 
same time, the practice of physiotherapy has become more complex due to changes in health care systems that have led to higher expectations for physiotherapists to diagnose and treat patients under increasingly time-pressured circumstances.

This thesis addresses issues concerning the implementation of EBP in physiotherapy. The four studies explore various conditions, at various levels, from the individual to the extra-organizational level, for the use of research in everyday physiotherapy practice, to achieve a more EBP in physiotherapy. Awareness and knowledge about the factors that provide important conditions for physiotherapists' use of research in routine practice may facilitate better implementation strategies to attain the goals of EBP. 


\section{BACKGROUND}

This chapter provides background information on physiotherapy, describing the history and evolution of this profession. A theoretical framework concerning the concept of EBP and implementation of EBP in health care is also provided. Previous research on implementation of EBP in physiotherapy is reviewed.

\subsection{Physiotherapy}

Physiotherapy is the third largest profession within health care in Sweden, after physicians and nurses (Broberg and Tyni-Lenné, 2009). The theoretical basis of the science of physiotherapy has its origin in different disciplines: the humanities, medical sciences, social sciences and behavioural sciences (Broberg and Tyni-Lenné, 2009).

Physiotherapy has been defined by the World Confederation of Physical Therapy (WCPT, 2011) as a profession that is concerned with "identifying and maximizing quality of life and movement potential within the spheres of promotion, prevention, treatment/intervention, habilitation and rehabilitation". The Australian Physiotherapy Council (APC, 2013) defines it as a profession that "involves the holistic approach to the prevention, diagnosis and therapeutic management of pain, disorders of movement or optimization of function to enhance the health and welfare of the community from an individual or population perspective."

Although there are many definitions of physiotherapy from around the world, there is consensus that the "movement system" is the core expertise of physiotherapy; the human movement system is a system of physiological organ systems that interact to produce and support movement of the body and its parts (Jull and Moore, 2013). Recognized physiotherapists advocate aligning the profession with a body system to gain recognition for its area of expertise, the "movement system" (Ludewig et al., 2013). The American Physical Therapy Association (APTA, 2013) highlights the need for a scientific definition of the movement system for physiotherapy to have a research area of expertise and 
an identity. Furthermore, APTA states that a goal for clinical research in physical therapy is to "encourage dissemination and utilization of clinical research related to physical therapy" (APTA, 2013).

Sweden has a strong tradition of physiotherapy. The origin of physiotherapy is the medical gymnastics developed at the beginning of the 19th century by Per Henrik Ling, who is also called the Father of Swedish Gymnastics (Broberg and Tyni-Lenné, 2009). In 1813, Ling established what is now called the Swedish School of Sport and Health Sciences with King Karl XIII as a protector (GIH, 2015). Physiotherapists at that time could receive a professor's title from the king without being physicians (Ottosson, 2013) although physiotherapy was not established as a licensed profession until the late 1800s. In 1887, physiotherapy become officially recognized and different treatments were registered in (what is now) the National Board of Health and Welfare. Physiotherapy was the second health care profession after physicians to be registered by the National Board of Health and Welfare (Ottosson, 2005).

Although physiotherapy today is mostly associated with rehabilitation after injuries, sickness or operations, during the 1800s the physiotherapist diagnosed and treated a variety of dieses, e.g. gonorrhoea, cardiac weakness and scoliosis. Based on diagnoses made by the physiotherapist, he or she combined individually adjusted movements and manipulations on the patient. The patient could also receive these movements as a prescription to perform by themselves at home (somewhat similar to today's physical activity on prescription).

In many ways, Sweden pioneered physiotherapy. The professional identity of physiotherapists and the knowledge base within physiotherapy were first established in Sweden, before spreading to Europe and the United States. In the late 1800s and early 1900s, physiotherapy institutions were founded all over the world, e.g. Chartered Society of Physiotherapy in Great Britain in 1894, School of Physiotherapy at the University of Otago in New Zealand in 1913 and Reed College in Portland, Oregon in 1914.

The physiotherapy profession in Sweden has been engaged in some power struggles with physicians. From the outset, the profession was dominated by men with no female physiotherapists in the profession at all in the middle of 1800s. An investigation by physicians into physiotherapy in 1930 proposed that men should be prohibited from becoming physiotherapists because they 
were considered too autonomous and did not follow orders from physicians; female physiotherapists were believed to be more obedient (Ottosson, 2005). The 1930 investigation did not go through, but it led to a reorganization of physiotherapy education at the Swedish School of Sport and Health Sciences. The education lost its status and the methods was deemed unscientific, the admission requirements were lowered and the education was shortened. These changes had the effect that male physiotherapists almost disappeared and physiotherapy as a scientific field was weakened.

In the 1800s, many physicians, particularly orthopaedics, worked as physiotherapists because they desired the scientific and professional status that the physiotherapy profession had; the status of orthopaedics was lower than that of physiotherapists in the first half of the 1800s (Ottosson, 2005). In the 1900s, the physiotherapy profession lost some of its status in relation to physicians regarding authority and acknowledgement for their methods. More women became physiotherapists, but they did not have free access to higher education. Male physiotherapists could enrol in higher education, which made it easier for them to achieve professional legitimacy and "compete" with physicians.

In 1977, physiotherapy became an academic education in Sweden. In 1993, this education was extended from two years to three years and physiotherapists were permitted to become PhD students; a Master's degree (two years) in physiotherapy has been available since 2007. The first physiotherapist in Sweden to defend her dissertation thesis was in 1981. Today, approximately 350 physiotherapists hold a $\mathrm{PhD}$ degree and there are more than 20 professors in physiotherapy in Sweden (LSR, 2013). There are approximately 21,500 authorized physiotherapists in Sweden (Socialstyrelsen, 2015). Physiotherapists are employed by county councils, the municipality (public sector) or they are selfemployed as entrepreneurs (private sector).

Today, physiotherapy is an independent, autonomous profession with its own scientific research field (Broberg and Tyni-Lenné, 2009). Physiotherapists in Sweden have a great deal of autonomy and the status of the profession has been strengthened. Physiotherapists in Sweden can choose and pursue any diagnostic and treatment approach they believe is suitable for the individual patient. The patients do not need a referral from a physician to consult a physiotherapist, which is the case in many countries. Patients can choose physiotherapists both from the private and public sectors (with the charge usually 
being the same although it depends on if the self-employed entrepreneurs are contracted to a county council or not).

\subsection{Evidence-based practice}

EBP has its roots in evidence-based medicine (EBM), which emerged in the 1990s in response to criticisms that medical research was considered methodologically weak. The rise and spread of the EBP movement has led to increased focus on the importance of wider uptake of research in health care and beyond. This section provides a brief background to EBP. The origins of EBP are described, followed by a definition of the concept of EBP and how it has been understood and interpreted.

\subsubsection{From evidence-based medicine to evidence- based practice}

EBM was conceived at McMaster University in Toronto, Canada, as a new approach to teaching the practice of medicine. It was introduced in 1992 in the Journal of the American Medical Association with a proclamation by the Evidence Based Medicine Working Group, a group of medical researchers and practitioners based at McMaster University (Evidence-Based Medicine Working Group, 1992; page 2420):

A new paradigm for medical practice is emerging. Evidence-based medicine de-emphasizes intuition, unsystematic clinical experience, and pathophysiologic rationale as sufficient grounds for clinical decision making and stresses the examination of evidence from clinical research. Evidence-based medicine requires new skills of the physician, including efficient literature searching and the application of formal rules of evidence evaluating the clinical literature.

This challenge to traditional medical education and practice may have seemed quite bold at the time, but two decades later the importance of EBM's ideals cannot be overestimated. Under the generic title of EBP, key concepts and principles of EBM have influenced many other professions, fields and disciplines, far beyond EBM's origins in medicine. Indeed, EBP now permeates 
most health-related fields, including physiotherapy, nursing, dentistry and mental health. EBP has also spread to more "distant" fields of social work, probation, education and management.

Definitions of EBP usually draw on a widely quoted definition of EBM by Sackett et al. (1996; page 71), who declared this to be:

The conscientious, explicit and judicious use of current best evidence in making decisions about the care of individual patients.

Although this definition was originally described in relation to EBM, it is often extended beyond the medical profession and has been adopted with slight modifications by many professions and in many practice settings, including physiotherapy.

Most definitions of EBP describe the concept in terms of integrating three knowledge sources: research (i.e. research-based knowledge), professional expertise (the practitioner's experience-based knowledge) and the patient's values and priorities. This tripartite EBP model is typically depicted with three overlapping circles, where the intersection is represented by practicing or "doing" EBP. This model has been expanded and today EBP is often described with the addition of a fourth component in the form of "resources" or "information from the practice context" (e.g. Haynes et al., 2002). An example of a more holistic definition of EBP is the following from the Sicily statement (Dawes et al., 2005; page 7):

Evidence-based practice (EBP) requires that decisions about health and social care are based on the best available, current, valid and relevant evidence. These decisions should be made by those receiving care, informed by the tacit and explicit knowledge of those providing care, within the context of available resources.

Many stakeholders are involved in the dissemination of the evidence-based model: government agencies (e.g. the Swedish Council on Health Technology Assessment (SBU), the National Board of Health and Welfare (Socialstyrelsen), Swedish Association of Local Authorities and Regions (SKL), international organizations (World Health Organization), networks of researchers and practitioners (e.g. Cochrane Effective Practice and Organization of Care Group 
(EPOC) and the Campbell Collaboration), professional organizations and many individual decision makers and opinion leaders.

Many factors have contributed to the rise and spread of the evidence-based movement. Developments in information technology have been important, especially electronic databases and the Internet, which have enabled practitioners to identify, collate, disseminate and access research on a global scale. However, the principles of EBP also tie in with many contemporary societal issues and concerns. EBP echoes the emergence of managerialism and the "audit society", with increased emphasis on issues of effectiveness, quality, accountability and transparency. Furthermore, it has been suggested that science promises a sense of security, rationality and reason in an "age of anxiety" where the influence of traditional authorities has decreased (Giddens, 1993; Dunnant and Porter, 1996; Trinder, 2000). Thus, EBP can be seen as a product of its time.

\subsubsection{Conceptualising evidence-based practice}

This thesis deals with research use and implementation of EBP in physiotherapy. It is important to emphasize that EBP is a broader concept than merely research use because research is one of the three knowledge sources specified in the definitions of EBP. However, EBP cannot be achieved without practitioners' use of research in their regular practice. Hence, the broader term, "implementation of EBP", is assumed to encompass issues concerning "research use".

Physiotherapists (and other professions in health care) have always relied on their experience-based knowledge and accounted for the patient circumstances in one way or another, but the evidence-based movement has put the focus on the importance of using research in routine practice. Implementation science has emerged in the wake of EBP with ambitions to understand and explain the challenges involved in realizing EBP by means of increased research use.

Over time, three different conceptualizations of EBP have emerged (Olsson, 2007)

- EBP as a critical appraisal procedure

- EBP as clinical guidelines

- EBP as specific practices with empirical research support 
Originally, the term EBP was applied to define a set of actions concerned with how research is critically appraised by practitioners and incorporated into their decisions. According to this conceptualization, EBP is a decision-making process comprising five steps (Sackett et al., 2000):

(1) Formulate an answerable question from the client's problems;

(2) Find the best relevant evidence;

(3) Critically appraise its validity and usefulness;

(4) Integrate this appraisal with clinical practice and clients values; and

(5) Assess performance.

The decision-making process approach to achieving an EBP focuses on the development of "research literacy" (also referred to as "EBP skills"), i.e. a skill set to consume, interpret and apply the research evidence within the context of practitioner experience and patient factors. A wealth of textbooks and continuing education courses that teach these skills are available. However, research has documented numerous barriers, from the individual level to the organizational level, to implementing and realizing the decision-making process approach to EBP (Straus et al., 2009). This is also the case within physiotherapy (this is described in Section 2.5).

Due to the many challenges in integrating a full decision-making procedure into routine health care practice, appraisal of evidence has increasingly been "outsourced" to specialists outside the practice setting, e.g. to groups such as the Cochrane Collaboration and Campbell Collaboration. Findings from research studies are synthesized in meta-analyses and systematic reviews, which provide information for guidelines produced by authorities and professional bodies. This development has led to the use of guidelines (and other types of summarized research findings) becoming synonymous with EBP in some areas (Olsson, 2007). Guidelines have been promoted as a far more realistic way to attain a more EBP.

Furthermore, EBP has come to be understood to involve specific practices, e.g. certain diagnostic or treatment interventions (methods, programmes, etc.), which have shown effectiveness in outcomes research, i.e. "evidence-based practices". EBP in terms of empirically supported practices focuses on the "products" of various health services, rather than on individual practitioners' process of decision making (Soydan and Palinkas, 2014). 


\subsection{Implementation theory}

Implementation science, a relatively young research field, seeks to address the challenges of using research to achieve an EBP in various practice settings. The journal Implementation Science was launched in 2006. Implementation science has been defined as the scientific study of methods to promote the systematic uptake of research and other evidence-based practices into routine practice to improve the quality and effectiveness of health services and care (Eccles and Mittman, 2006). This section describes the origins of implementation science and theories relevant to the studies on implementation of EBP in this thesis.

\subsubsection{Origins of and influences on implementation science}

Although implementation science is a relatively new concept (and research field), there are numerous terms that describe overlapping and interrelated research, for example knowledge translation, knowledge exchange, knowledge transfer, knowledge integration, research use (also referred to as research utilization). These concepts all refer to research on putting various forms of knowledge (including research) to use in practice settings (Nilsen, 2015). It is also relevant to point out that implementation is closely associated with the concepts of diffusion and dissemination. Indeed, the field of implementation is sometimes referred to as "implementation and dissemination". Diffusion, dissemination and implementation are usually described on a continuum: diffusion is the passive spread of new practices; dissemination is the active spread of new practices to a target audience using planned strategies; and implementation is the process of putting to use or integrating new practices within a setting (Greenhalgh et al., 2004; Brownson et al., 2012).

Influences on implementation science have come from research in several fields and research traditions. Research on the diffusion of innovations, as described as part of the Theory of Diffusion (popularized through Rogers' 1962 book Diffusion of Innovations), has been an important influence. For instance, the theory's so-called innovation attributes, i.e. relative advantage, compatibility, complexity, trialability and observability, have been widely applied in implementation science to assess the extent to which the characteristics of the implemented practice (e.g. a new treatment method or a clinical guideline) 
affect implementation outcomes. Another feature of the Theory of Diffusion is its emphasis on the importance of intermediary actors (opinion leaders, change agents and gate-keepers) for successful implementation. Similar actors or roles are described in several frameworks and models that are used in implementation science (Nilsen, 2015).

Another obvious influence on implementation science is research on policy implementation, which was a prominent social science research field in the 1970s during a period of growing concern about the effectiveness of public policy. Pressman and Wildavsky's (1973) book entitled Implementation popularized the concept of implementation. Research on policy implementation emerged from the insight that political intentions seldom resulted in the planned changes, which encouraged researchers to investigate what occurred in the process and how it affected the results (Nilsen et al., 2013).

Still another important influence on implementation science is research on research use (also referred to as research utilization). This field developed in the 1980s out of the social science research field of knowledge utilization, which was established in the 1970s. Nursing researchers borrowed many concepts from the knowledge utilization field to investigate the extent to which nurses used research in routine practice and influences on their research use (Estabrooks et al., 2006; Squires et al., 2011). It is customary to distinguish between three types of research use: instrumental use is research that is directly applied in decisions concerning care or treatment of patients; conceptual use is research used for purposes of general enlightenment, to provide new concepts, ideas and perspectives that might be useful in a more indirect way; and persuasive use is research use to persuade others, with the aim of influencing, for example, resource allocation or policies (Weiss, 1979; Estabrooks, 1999).

Implementation researchers have developed numerous so-called determinant frameworks. These multi-level frameworks link theories to various types of determinants that affect the implementation outcomes. A determinant is made up of one or several barriers and/or facilitators (Nilsen, 2015). The frameworks differ with regard to many details, but they usually account for the same six types of determinants, as described in Table 1. 
Table 1. Implementation determinants (adapted from Nilsen, 2015)

\begin{tabular}{ll}
\hline Type of implementation determinant & Explanation \\
\hline Implementation object & $\begin{array}{l}\text { The "object" that is implemented is usu- } \\
\text { ally an evidence-based practice, i.e. an } \\
\text { intervention, method, routine, etc. that } \\
\text { has research support. Characteristics of } \\
\text { this object (e.g. perceived complexity, } \\
\text { relative advantage and compatibility } \\
\text { with existing practices) influence imple- } \\
\text { mentation outcomes } \\
\text { The effectiveness of the strategies (e.g. } \\
\text { guidelines, continuing professional edu- } \\
\text { cation) used to facilitate the effect of im- } \\
\text { plementation on the outcomes } \\
\text { Potential and actual users of the imple- } \\
\text { mentation object have various character- } \\
\text { istics (e.g. attitudes, motivation, educa- } \\
\text { tional level, years in the occupation) that } \\
\text { affect implementation } \\
\text { Implementation can be influenced by } \\
\text { actors other than the health care practi- } \\
\text { tioners, such as patients and policy mak- } \\
\text { ers } \\
\text { Implementation actors } \\
\text { Thentaracteristics of the organization or } \\
\text { unit in which implementation occurs can } \\
\text { affect the processes and outcomes of } \\
\text { implementation } \\
\text { Conditions at extra-organizational levels, } \\
\text { such as society at large, can influence } \\
\text { implementation, for instance by means } \\
\text { of laws, regulations, societal norms and } \\
\text { population demographics }\end{array}$ \\
Outer context &
\end{tabular}

\subsection{Theories used in the thesis}

Three of the four studies of this thesis (Studies I, III and IV) were explicitly guided by the use of several different theories to provide the best possible understanding and explanation of the challenges of implementing EBP addressed in the studies. The theories are briefly described here. 


\subsubsection{Individual-level behaviour change theories}

Study I of this thesis applied a social-cognitive theory called SelfDetermination Theory. This theory is one of many theories from psychology that are used in implementation science to study influences on "clinical behaviour" change. These theories are relevant because it is usually the individual practitioner who ultimately decides whether or not to use a new evidencebased diagnostic or treatment method. In general, these theories focus on individual cognitions or thoughts as processes, which intervene between observable stimuli and responses in specific real-world situations. Essentially, social cognition is concerned with how individuals make sense of social situations (Conner and Norman, 2005). Social-cognitive theories such as the Theory of Reasoned Action (Fishbein and Ajzen, 1975; Ajzen and Fishbein 1980) the Social Cognitive Theory (Bandura, 1977, 1986), the Theory of Interpersonal Behaviour (Triandis, 1989) and the Theory of Planned Behaviour (Ajzen, 1991) have all been widely used in implementation science.

Self-Determination Theory concerns motivation. It posits that all behaviours (for instance the use of research in clinical practice) lie along a continuum of relative autonomy, i.e. self-determination, reflecting the extent to which a person endorses what he or she is doing (Deci and Ryan, 1985). At one end of the self-determination continuum is behaviour that is intrinsically motivated and performed for its inherent satisfaction, e.g. for the fun, interest or challenge it offers. At the other end is amotivation, which is a lack of intention to perform the behaviour. In between intrinsically motivated behaviours and amotivation lie extrinsically motivated behaviours, meaning that they are performed to obtain certain results in contrast to intrinsic behaviours, which are performed for their own sake.

\subsubsection{Individual and organizational learning theories}

Study III explored individual and organizational learning in relation to physiotherapists' participation in a research project relevant to their professional development to achieve a more evidence-based physiotherapy. There is no generally accepted definition of learning, yet there is considerable consensus among learning theorists that learning implies some sort of lasting change and that the individual in some way is different from before the learning took place (Argyris and Schon, 1974; Ellström, 1992). 
The concept of learning has been defined and understood differently by different learning theorists, with variation across time and traditions. Behaviourism considers learning in terms of behaviour change, with learning being the result of the individual's response to a stimulus (e.g. provision of information or demonstration of a skill). Cognitive theories consider behaviour as the deliberate outcome of perceptions, beliefs, motivation, memory and understanding. Social cognitivism posits that much of what individuals learn is also influenced by the observation of others. Constructivism assumes that learning occurs when knowledge is constructed by the learner. Although constructivism is usually described as a variety of cognitivism (because it assumes that learning involves cognitive processes), these approaches to learning refute the idea that there is knowledge "out there", independent of the person who has the knowledge. Instead, it is argued that learning is a personal construction of meaning out of our own experience (Jarvis et al., 2003; Phillips and Soltis, 2009) and learning emerges in the interactions between people and in the dynamic interdependence between context and individual processes (JohnSteiner and Mahn, 1996).

Organizations are often assumed to learn analogously to individuals, with concepts used in various individual learning theories being extended to the organizational level (Easterby-Smith and Lyles, 2011). Definitions of organizational learning tend to emphasize that this learning implies some type of change, i.e. analogous to how individual learning is usually defined. These changes are typically understood broadly, in terms of changes in organizational capacity or changes in potential behaviours (Kim, 1993; Ellström, 2010).

Most organizational learning theorists agree that individual learning is a necessary, but not sufficient, condition for organizational learning (Ellström, 2010). However, organizational learning is more complex than merely being a magnification of individual learning. An important issue in research on organizational learning is how the links between individual and organizational learning look like and how individual learning can be transformed into organization learning (Kim, 1993). Several researchers (e.g. Dixon, 1997; Schein, 1993; Oswick, 2000) have highlighted that organizational learning cannot occur without a dialogue between individuals, groups and the organization system. Such a dialogue is the process of joint construction of meaning and understanding (Dixon, 1997; Schein, 1993; Oswick, 2000). 


\subsubsection{Organizational theories: culture and leadership}

Study IV explored how physiotherapy leaders influence the culture for the implementation of evidence-based physiotherapy practice. There is increasing recognition in implementation science of the relevance of the organizational context, including leadership and organizational culture influences, which are beyond the individual level (Nilsen et al., 2012; Dannapfel et al., 2013; Greenhalgh et al., 2004; Stetler et al., 2009; Davis, 2010; McCormack et al., 2009; Cummings et al., 2007; Latta, 2009; Aarons et al., 2014a; Nutley et al., 2007; Rycroft-Malone, 2008; Damschroder et al., 2009; Gurses et al., 2010). Many of the individual barriers to implementation of EBP, e.g. lack of time to search for and appraise research and insufficient support for this process, have been linked to leadership and cultural issues, suggesting the context is an important influence on implementing EBP (Sibbald et al., 2015; Williams et al., 2015; Nutley et al., 2007).

Although there is no universally agreed definition of leadership, many conceptualizations reflect the assumption that leadership involves a process of exerting intentional influence by one person over another person or group in order to achieve a certain outcome in a group or organization (Yukl, 2006). There is a debate regarding whether the concepts of manager and leader can be used interchangeably or if they are two different concepts with two exclusively different roles (Gifford and Davies, 2008). In leadership theory, there is no agreement on that question, however recent leadership theories argue that both management and leadership can be carried out by the same person and what is needed at the time depends on the situation and context (Reichenpfader et al., 2015; Kotter, 1990). For successful change to happen, Pettigrew et al. (1992) suggested that inspiring leaders and a supportive context are facilitators.

Numerous leadership theories have been developed over the years. Perhaps the most widely applied theory in recent years is that of transformational leadership (Aarons et al., 2014a). This style of leadership has been described as being inspirational, motivational, people-oriented, accepting of differences and having an idealized influence on subordinates (Yukl, 2006). Transformational leadership is a process in which leaders and followers help each other to advance to a higher level of morale and motivation (Bass, 1985). Furthermore, these leaders, according to Bass, encourage people to be creative and critical and to challenge the status quo in order to find new ways of doing things. 
Transformational leaders are often visionary and good at communicating their goals (Bass, 1985).

A great deal of research has highlighted the importance of transformational leadership for organizational performance (Howell and Avolio, 1993; Yammarino et al., 1993; Yukl, 2006). For example, research has found a relationship between transformational leadership and organizational commitment (Avolio et al., 2004; Searle-Leach, 2005; Bycio et al., 1995); job satisfaction (Podsakoff et al., 1996; Walumbwa et al., 2005) and communicating planned organizational change (Battilana et al., 2010) influence attitudes towards EBP (Moser et al., 2004; Aarons, 2006; Sandström et al., 2011) and commitment to change (Hill et al., 2012; Damanpour and Schneider, 2006; Jung et al., 2003; Gumusluoglu and Ilsev, 2009), research utilization (Kajermo et al., 2008) and implementation of guidelines (Marchionni and Ritchie, 2008). Research has also found that culture and climate for improvement are better with leadership support (Ginsburg et al., 2005; Hallencruetz, 2012).

Leadership and organizational culture have been described as two sides of the same coin. Leaders have a crucial role in shaping the culture of an organization, yet the culture of an organization determines who can become a leader in the organization (Schein, 2004; Clarke et al., 2011; Schein, 2010). Organizational culture has been defined as the shared values (important and lasting ideals and preferences for certain behaviours) and norms (beliefs about acceptable behaviours) and assumptions (unspoken beliefs and expectations) among members of an organization or group (Bang, 2009). An organizational culture comprises multiple subcultures, typically of a professional, departmental or geographic kind (Gill, 2011).

Schein (2010) emphasizes the importance of unconscious taken-for-granted assumptions. He describes organizational culture as a process of dynamic learning and defines it as "the pattern of basic assumptions which a given group has invented, discovered, or developed in learning to cope with its problem of external adaption and internal integration, which have worked well enough to be considered valid and, therefore, to be taught to new members as the correct way to perceive, think and feel in relation to those problems" (Schein, 2004; page 17). Schein's basic assumptions are similar to what Argyris (1976) identifies as theories-in-use, referring to assumptions that are tacit but that actually guide the group's behaviour, how to think, feel about and perceive things. Schein (2004) describes culture as a dynamic learning 
process, which implies that culture changes over time. However, that is not always the case. Two scenarios are described as response to change or problem solving: (1) positive problem solving, abandon the old way in response to a problem/change; (2) continue the same way solving the problem as usual to avoid anxiety, which is often the reason why responses that are no longer valid are repeated (Schein, 2004).

\subsection{Previous research on implementation of evidence-based practice in physiotherapy}

Research has documented that physiotherapists generally believe that EBP:

- can improve the quality of patient care (Barnard and Wiles, 2001; Jette et al., 2003; Salbach et al., 2007; Akinbo et al., 2009; Nilsagård and Lohse, 2010; Heiwe et al., 2011)

- is helpful for making decisions about patient care (Jette et al., 2003; Salbach et al., 2007; Akinbo et al., 2009; Heiwe et al., 2011)

- can enhance the status of the physiotherapist profession (Barnard and Wiles, 2001; Hannes et al., 2009)

- can facilitate an increased reimbursement rate if EBP is incorporated into their clinical practice (Jette et al., 2003; Akinbo et al., 2009; Heiwe et al., 2011)

- can yield improved relationships with other health professions as well as better working conditions (Barnard and Wiles, 2001)

In general, physiotherapists hold favourable attitudes towards EBP and believe it is important that practice is based on the most up-to-date evidence available (Barnard and Wiles, 2001; Kamwendo, 2002; Stevenson et al., 2004; Iles and Davidson, 2006; Grimmer-Somers et al., 2007; Caldwell et al., 2007; Nilsagård and Lohse, 2010; Heiwe et al., 2011). However, these attitudes do not seem to be fully "translated" into clinical practice, as many studies have shown that physiotherapists continue to make decisions based on knowledge obtained during their initial education and/or personal experience, rather than findings from research (Overmeer et al., 2004; Mikhail et al., 2005; Bridges et al., 2007; Heiwe et al., 2011; Filbay et al., 2012). 
Studies have identified several barriers to physiotherapists' use of research findings:

- poor confidence in skills to identify and critically appraise research (Hannes et al., 2009; Salbach et al., 2007; Grimmer-Somers et al., 2007; Stevenson et al., 2004; Palfreyman et al., 2003)

- insufficient time due to patient work commitments (Swinkels et al., 2011; Fruth et al., 2010; Kamwedo et al., 2002)

- insufficient support from colleagues (Salbach et al., 2007)

- perceived isolation from peers (Grimmer-Somers et al., 2007)

- inadequate support from managers and other health professionals (Barnard and Wiles, 2001; Swinkels et al., 2011; Hannes et al., 2009; Bekkering et al., 2003)

- poor access to Web-based research resources and computer skills (Salbach et al., 2007)

It is noteworthy that the research findings concerning implementation of EBP in physiotherapy are quite similar to those pertaining to other professions in health care. Indeed, barriers to achieving a more EBP in health care have become fairly well established in many studies since the late 1990s. They include factors such as time restrictions, limited access to research, poor confidence in skills to identify relevant research, poor confidence to critique research, difficulties in interpreting guidelines and inadequate support from colleagues and managers/leaders (Rycroft-Malone and Bucknall, 2010; Mittman, 2012).

With regard to implementation strategies (i.e. implementation interventions directed at health care practitioners) to facilitate implementation of EBP in physiotherapy, research has shown that educational interventions to achieve increased EBP tend to have modest impact on physiotherapists' clinical practice (Stevenson et al., 2006; Fruth et al., 2010). Clinical guidelines represent another strategy to facilitate the use of research findings in clinical practice. Two systematic reviews of interventions aimed at facilitating guideline implementation in physiotherapy (Van der Wees et al., 2008; Menon et al., 2009) have concluded that active, multifaceted strategies were superior to passive strategies for improving knowledge and changing behaviour, but they had no significant effect on patient health or costs of care. There is tentative evidence from two non-randomized trials that guideline adherence can improve patient health outcomes and reduce costs (Fritz et al., 2007; Rutten et al., 2010). 


\section{RATIONALE}

The thesis comprises four articles that explore issues related to the conditions for implementation of EBP in physiotherapy. The intention has been to provide an in-depth, holistic understanding of this complex phenomenon. The studies were specifically designed to address key knowledge gaps that could be identified in previous research on EBP in physiotherapy. Studies III and IV also sought to account for the findings that emerged in Studies I and II.

Physiotherapy research has identified numerous social-cognitive variables, such as beliefs, attitudes and self-efficacy, which affect physiotherapists' use of research and implementation of EBP. However, previous studies have not explored the different reasons or different types of motivations that practitioners may have for using research in their clinical practice. Motivation (or intention) is the most proximate determinant of behavioural enactment in many socialcognitive theories, including the widely applied Social Cognitive Theory and the Theory of Reasoned Action. This suggests that motivation might be a better predictor of behaviour than the more distal variables such as attitudes, beliefs and self-efficacy. Therefore, Study I was aimed at exploring different types of motivation behind physiotherapists' use of research in their clinical practice. The Self-Determination Theory was applied to identify and distinguish between different types of motivation for the use of research.

Previous research on implementation of EBP in physiotherapy has predominantly focused on survey-based "barrier studies". However, it is not selfevident that the removal or reduction of these barriers yields increased use of research in clinical practice. Therefore, it is also important to investigate the various circumstances that physiotherapists have found to actually support their use of research in routine practice. Based on this premise, Study II explored various conditions at different system levels that physiotherapists perceived to be supportive of their research use in clinical practice.

Existing research on implementation strategies to facilitate the implementation of EBP in physiotherapy has largely focused on educational interventions and clinical guidelines. However, research in other health fields has highlighted the potential of various forms of collaboration between health care practitioners and researchers to achieve increased EBP (Fixsen et al., 2005; Nutley et al., 
2007; Kitson et al., 2013). Study I also pointed to the relevance of engaging more autonomously motivated physiotherapists as change agents to create favourable conditions for colleagues' research use. Study II highlighted the potential that discussions and reflection with research colleagues can have to create a knowledgeable and research-oriented culture. Therefore, study III was designed to explore what physiotherapists might learn through participation in a research project and how and the extent to which this learning is transferred to colleagues for enhanced organizational learning.

Determinants of implementation of EBP in physiotherapy have predominantly been sought at the individual physiotherapist level. However, there is an increasing recognition within implementation science of the relevance of the organizational context, i.e. influences beyond the individual level (Cummings et al., 2007; Stetler et al., 2009). Studies I and II also indicated that many factors influencing research use can be found at levels "above" the individual physiotherapist. Organizational culture has been identified as a potentially important influence on health care practitioners' use of research in their everyday practice. Many of the individual barriers, such as lack of time to search for and appraise research and insufficient support for this process; can be linked to cultural issues. Hence, numerous researchers (e.g. Funk et al., 1995; Aarons et al., 2014b; Nutley et al., 2007) have argued that the culture is in fact the primary inhibiting factor for implementing EBP in many practice settings. However, research is still relatively limited regarding the impact of culture and leadership on the implementation of EBP in physiotherapy (and health care in general). Against this backdrop, Study IV explored how leaders in physiotherapy can influence the culture for EBP implementation. 


\section{AIMS}

The overarching aim of this thesis was to explore conditions at different levels, from the individual level to the organizational level and beyond, for the use of research and implementation of an evidence-based physiotherapy practice.

More specifically, the following research questions were addressed in the four studies:

Study I: What types of motivation underlie physiotherapists' research use in their clinical practice?

Study II: What conditions at different system levels are supportive of physiotherapists' research use in clinical practice?

Study III: What do physiotherapists learn through participation in a research project relevant to their professional development, and to what extent is this learning transferred to their colleagues and the wider organization?

Study IV: How do physiotherapy leaders influence the culture for the implementation of evidence-based physiotherapy practice? 


\section{METHODS}

This chapter provides details about the methods used in the four studies of the dissertation. An overview of the methods is presented first, followed by a description of the study settings, study participants, data collection and data analysis. Finally, some ethical considerations are addressed.

\subsection{Overview of the methods}

A few different qualitative data collection and data analysis approaches were used in this dissertation to address the research questions. This variety was deemed necessary to approach the topic in a holistic manner and to account for different system levels to explore conditions for implementation of EBP in physiotherapy. The research has developed from considerations regarding purposeful methods for data collection and analysis in order to respond to the overall aim of the thesis and the specific aims of the four studies. Table 2 summarizes the key characteristics of the four studies.

The research project started with the aim of exploring motivations behind physiotherapists' use of research in their clinical practice (Study I). Data were obtained from focus group interviews in various settings in Sweden. Data were analysed using conventional content analysis (Hsieh and Shannon, 2005) and the findings were compared with Self-Determination Theory using a deductive approach (Ryan and Deci, 2000).

Study II explored facilitation of EBP at different levels, from the individual level to the organizational level. This study was based on the same data as the first study. However, the data were analysed using an inductive approach, applying qualitative content analysis. This study provides an understanding of the conditions that foster physiotherapists' use of research in clinical practice.

Study III aimed to investigate physiotherapists' experiences and learning from participating in a research project, which involved provision of a neck-specific 
exercise intervention to patients. Qualitative in-depth interviews with an open-ended structure were chosen as the method of inquiry.

Study IV was also a qualitative in-depth study that involved interviews with managers about EBP and research use, to explore the influence of leadership on the "EBP culture". The interview questions were inspired by a framework developed by Schein (2010) that identifies a number mechanisms by which leaders can influence the culture of an organization and/or groups within an organization. Schein's framework was also used to analyse the empirical data.

Table 2: Overview of the four studies of the thesis

\begin{tabular}{|c|c|c|c|c|}
\hline Study & Aim & $\begin{array}{l}\text { Study participants } \\
\text { and settings }\end{array}$ & Data collection & Data analysis \\
\hline I & $\begin{array}{l}\text { Explore the } \\
\text { motivation behind } \\
\text { physiotherapists' use } \\
\text { of research in their } \\
\text { clinical practice }\end{array}$ & $\begin{array}{l}\text { Physiotherapists in } \\
\text { primary care, } \\
\text { hospitals and } \\
\text { private clinics }\end{array}$ & $\begin{array}{l}\text { Focus group } \\
\text { interviews }\end{array}$ & $\begin{array}{l}\text { Deduction; } \\
\text { qualitative } \\
\text { content analysis } \\
\text { (Kripendorff, } \\
\text { 2004) }\end{array}$ \\
\hline II & $\begin{array}{l}\text { Explore the } \\
\text { conditions that } \\
\text { physiotherapists } \\
\text { perceived to be } \\
\text { conducive to } \\
\text { research use }\end{array}$ & $\begin{array}{l}\text { Physiotherapists in } \\
\text { primary care, } \\
\text { hospitals and } \\
\text { private clinics }\end{array}$ & $\begin{array}{l}\text { Focus group } \\
\text { interviews }\end{array}$ & $\begin{array}{l}\text { Induction; } \\
\text { qualitative } \\
\text { content analysis } \\
\text { (Kripendorff, } \\
\text { 2004) }\end{array}$ \\
\hline III & $\begin{array}{l}\text { Explore individual } \\
\text { and organizational } \\
\text { learning through } \\
\text { physiotherapists' } \\
\text { participation in a } \\
\text { research project }\end{array}$ & $\begin{array}{l}\text { Physiotherapists in } \\
\text { primary care and } \\
\text { private clinics who } \\
\text { were involved in an } \\
\text { intervention study }\end{array}$ & $\begin{array}{l}\text { Individual } \\
\text { interviews }\end{array}$ & $\begin{array}{l}\text { Induction; } \\
\text { hermeneutic } \\
\text { analysis } \\
\text { (Gadamer, } \\
\text { 2004) }\end{array}$ \\
\hline IV & $\begin{array}{l}\text { Explore how } \\
\text { physiotherapy } \\
\text { leaders influence the } \\
\text { culture for } \\
\text { implementation of } \\
\text { EBP in } \\
\text { physiotherapy }\end{array}$ & $\begin{array}{l}\text { Physiotherapists in } \\
\text { primary care and } \\
\text { hospital settings } \\
\text { holding a manager } \\
\text { position }\end{array}$ & $\begin{array}{l}\text { Individual } \\
\text { interviews }\end{array}$ & $\begin{array}{l}\text { Induction and } \\
\text { deduction; } \\
\text { direct content } \\
\text { analysis (Hsieh } \\
\text { and Shannon, } \\
\text { 2005) }\end{array}$ \\
\hline
\end{tabular}




\subsection{Study setting characteristics}

All studies were set in Sweden. Health care in Sweden is publicly funded, i.e. residents are insured by the state, with equal access for the entire population and fees regulated by law. The provision of health care services is the responsibility of the 21 county councils across Sweden. In November of 2013 approximately 21593 licenses had been issued, of these had 12523 an occupation in health care (Socialstyrelsen, 2015)

The local context differed between the studies. The data for Studies I and II were collected from five county councils in Sweden, from four clinics located in rural settings and seven in urban settings. There was also heterogeneity regarding the type of clinics: six were located in hospitals, three were primary care centres and two were private clinics. The data were obtained from 45 physiotherapists included in 11 focus groups.

Study III was conducted in southern Sweden where the neck-specific exercise intervention study was performed. The 20 physiotherapists involved in the neck-specific exercise intervention worked in different clinical settings including primary care and private clinics.

Study IV was also conducted with participants from different county councils in Sweden, from south to north. Data were collected by means of interviews with nine physiotherapists with managerial responsibility over different types of clinics, including primary care and hospital settings.

\subsection{Study participants and data collection}

Physiotherapists were the target population in all the studies. All participants except some of the physiotherapy managers in Study IV worked as physiotherapists in various clinical settings. The aim in all four studies was to have a heterogeneous sample of physiotherapists, differing with regard to (1) geographic location; (2) clinical context (3); age; (4) sex; (5) number of years in practice; (6) educational level. All interviews were performed by the author of the thesis. Interview guides were developed by myself in close collaboration with the researchers (i.e. co-authors) involved in the different studies (further details provided below). 
Studies I and II involved 45 physiotherapists who took part in 11 focus groups. The participants were recruited through managers and other key individuals in different clinical settings in Sweden via an e-mail that briefly described the study. The request was sent to a number of hospitals, primary care units and private clinics. All who answered positively were asked to invite physiotherapists in their clinic (department, unit, etc.) to participate in the study. They were encouraged to invite whole teams of physiotherapists to avoid bias due to selection of specific physiotherapists. Each focus group consisted of physiotherapists from the same workplace, but they did not necessarily work as part of the same team although they shared the same management.

Out of the 45 physiotherapists, 33 were female. The average age of the participants was 41 years (range 22-62 years; standard deviation (SD) 11.5 years) and the average length of work practice was 13 years (range 1-37 years; SD 9.2 years). They had an average of 3 years of basic education (range 2-5 years; SD 0.5 years) and two had a Master's degree. All had taken part in courses beyond their basic training; $82 \%$ had participated in non-academic courses and $64 \%$ had been involved in academic courses. Of the participants, 36 worked fulltime and nine were employed part-time.

The focus group interview guide for Studies I and II consisted of open-ended questions to facilitate flexibility during the interview. The guide developed by the authors of the two studies was scrutinized in a seminar with ten physiotherapists most of whom combined research with physiotherapy practice. The guide had three overarching questions: (1) "Registered physiotherapists are supposed to work in accordance with 'scientific evidence and trusted experience' - how is this expressed in your daily practice?" (2) "What are your reasons for using research in your clinical practice?" (3) "What conditions do you find supportive for the use of evidence based practice in your practice?"

Participants for Study III were physiotherapists involved in a physiotherapy research project, which was a prospective, randomized controlled multi-centre intervention study. The aim of this research project was to investigate whether neck-specific exercise with or without a behavioural intervention (performed by a physiotherapist) could improve functioning compared with a prescription of general physical activity for individuals with chronic (more than 6 months but less than 3 years) whiplash-associated disorders. Interviews were conducted with physiotherapists who treated patients in the neck-specific exercise 
group. Patients in this group performed neck-specific training (with the aim to improve muscle coordination pattern and neck muscle endurance), which was supervised by a physiotherapist twice a week for 3 months at the physiotherapy clinic, with additional exercises being performed at home. The physiotherapists participated in half a day of training on the theoretical and practical issues led by experienced physiotherapists from the research team. Twenty physiotherapists were involved in the neck-specific exercise intervention in the whiplash study. They were approached via an e-mail to take part in our study.

Eleven physiotherapists agreed to participate in Study III. Of the 11 physiotherapists, seven were female. The mean age was 44 years (range 26-35 years; SD 13.0 years). The length of time in practice was 19 years (range 3-40 years; SD 11.7 years). The data were gathered at different times and took place at the physiotherapists' workplace except one interview, which was held in the physiotherapist's home. Qualitative in-depth interviews with an open-ended structure were used (Patton, 2002). The semi-structured interview guide (using topics not questions) was developed by the three authors of the study and had been scrutinized in a seminar with researchers from different backgrounds. The topics used in the interviews were experiences of participating in the research project; learning from participating in the research project; and transfer of knowledge gained from participating in the research project.

The participants in Study IV worked as managers in different physiotherapy settings. A purposeful selection approach was used to achieve a heterogeneous sample of physiotherapy managers that represented a broad spectrum of experiences and contexts. They were recruited through an e-mail that briefly described the study. The e-mail request was sent to 30 managers who were identified through different county council websites with contact information for departments that employed physiotherapists. The managers were asked if they knew other managers who would be interested in participating in the study. Two of the participants were recruited via such a recommendation from a participating manager.

Of the nine managers in Study IV, six were female and three were male. Number of years as a manager in a health care organization varied between 11 months to 15 years (range 32-64 years; average age 44 years) and seven managers had a Bachelor's degree and two had a Master's degree. The number of employees in the departments in which the managers worked ranged from 12 to 370 . The interview guide was developed by the authors of the study and 
was scrutinized by two other researchers. Topics were used to explore the influence of the managers on the culture for implementation of evidence-based physiotherapy practice. The questions concerned how they as managers influenced and worked with EBP issues in their setting and how they perceived support and influence from their managers and the wider organization.

\subsection{Data analysis}

Data collected for Study I were analysed using conventional content analysis, which entails a structured analysis process to code and categorize data (Hsieh and Shannon, 2005). The first step involved all authors reading all transcripts to get a sense of the whole. Step two involved getting a sense of the data and the various key statements and thoughts in relation to the study aim. These statements were highlighted in the transcripts. During step three, codes were developed that reflected more than one key statement or thought. These codes were then aggregated into clusters based on similarity of the content and their relation to each other. After re-examination, the initial clusters were merged into categories. In the next step, the findings on the contents of the categories were compared and contrasted with Self-Determination Theory using a deductive approach. The categories were mapped onto the different types of motivation (i.e. pre-defined categories) specified in the theory.

Data in study II were analysed using qualitative content analysis in accordance with Krippendorff (2004). Several steps were undertaken in the analysis process. Initially, each author read all the transcripts to gain an understanding of the whole. The first author reviewed the transcripts and identified coding units in the text that captured key statements in relation to the study aim. All the researchers then scrutinized the coding units and they reviewed the text several times. The coding units were merged into context units by the three authors during this process. The context units included several coding units and reflected more than one key statement. Next, the the three authors combined the context units into categories based on similarity of the content. These categories were based on conditions that the focus group participants mentioned as being supportive of research use. This analysis of the data yielded nine categories that the participants discussed in relation to conditions that supported or facilitated research use in their clinical practice. In the next step, the categories were merged under three overarching system levels based on 
their characteristics: individual, workplace and extra-organizational levels. The analysis was inductive in all steps.

The data in Study III were analysed using Gadamer's (2004) hermeneutics. In a hermeneutic analysis, the researcher's preconceptions are a part of the analysis. One interpretation is dependent on the former interpretation, resulting in a new understanding created by the interpreter. Furthermore, understanding that the researcher has from earlier research is also included when interpreting the material. Understanding occurs when these horizons are fused with the researcher's perspective.

Four guiding principles were followed in the hermeneutic analysis in Study IV. The first principle involved reading the transcribed interviews several times to obtain a sense of the whole. The second principle involved re-reading the text and asking open questions: what is the understanding in the text; what does this stand for; what is the alternative interpretation; in what context is this being told. The analysis involved movement between the whole and its parts, participant by participant and dictum by dictum. Statements were found that created and elaborated meaning. The third principle required the text to be interpreted from the horizon of the interpreter with the addition of literature and facts. This step involved identification of clusters that provided a description and were representative of the overall text. The fourth principle involved fusion of the horizons from the participants and the interpreter. Once again, the verbatim transcription was reconsidered in relation to the horizons to validate and separate the horizons from each other. The focus was on finding expressions that contributed to an understanding of the physiotherapists' learning from participation in a research project. The data interpretation proceeded in a hermeneutic circle until consensus was reached.

The interview data from Study IV were analysed using direct content analysis in accordance with Hsieh and Shannon (2005). Content analysis is a technique for analysing texts based on empirical data with an explorative and descriptive character. A directed approach in content analysis is guided by a structured deductive process with the point of departure for coding being an existing theory or previous research. The data in Study IV were analysed and interpreted using a framework by Schein (2010), which describes a number of socalled embedding mechanisms that explain how leaders can influence the culture of an organization. The first step involved both authors reading all transcripts to obtain an understanding of the whole. The authors separately coded 
the transcripts, using the directed content analysis approach and Schein's embedding mechanisms as a framework to structure, code and categorize the data. The framework was used to determine the initial coding and relationships between the codes. Data that could not be coded or identified in relation to Schein's framework were analysed later to determine if the data represented a new category or a subcategory of an existing category (Hsieh and Shannon, 2005).

\subsection{Ethical considerations}

The four studies were based on statements and narratives from respondents through individual interviews and focus group interviews. The moral integrity of the researcher is a critically important aspect of ensuring that the research process and a researcher's findings are trustworthy and valid. All four studies of this dissertation recognized the ethical principles for research. The basic principles for protecting participants were adhered to: i.e. information about the study was provided, informed consent was obtained, the purpose of the research was explained and assurance of confidentiality was given (Patton, 2002). Studies I and II were approved by the Regional Ethical Review Board in Linköping. No ethical approval was sought for Studies III and IV because these studies did not collect sensitive information and are thus not covered by the law on ethical reviews.

All participants in the four studies were informed about the aim of the study. The participants were also informed about the method (individual and focus group interviews), the research project, the name of the supervisors and were introduced to the author of this thesis. The participants were asked about being recorded and were informed about the data being transcribed for use in research, with the aim of publishing in a scientific journal. The participants were assured that all characteristics that could potentially reveal their identity would be decoded. All participants gave their informed consent. All questions asked were in regard to their working life and their knowledge of being a professional in their field. 


\section{FINDINGS FROM THE STUDIES}

This chapter contains the results in abbreviated form from the four empirical studies. The aim and main findings are presented for each study. The complete results for all studies are presented in the papers appended in the last section of the thesis.

\subsection{Study I}

This study investigated motivations behind physiotherapists' use of research in clinical practice. It addressed this research question:

- What types of motivation underlie physiotherapists' research use in their clinical practice?

The study identified ten different types of reasons for research use by the physiotherapists, which could be mapped onto the six categories of motivation described in the Self-Determination Theory: intrinsic motivation; integrated motivation; identified motivation; introjected motivation; externally regulated motivation; and amotivation. Intrinsic, integrated and identified types of motivation are labelled autonomous motivation, whereas introjected and externally regulation motivation are referred to as controlled motivation. Amotivation is a lack of motivation.

Some physiotherapists provided statements that showed that their research use was intrinsically motivated, driven by a genuine curiosity and willingness to learn. They described using research in their clinical practice for its own sake because they felt it was interesting and satisfying in itself. For them, research use was an opportunity rather than an obligation. Other physiotherapists depicted their use of research in terms that suggested that it was regulated by integration, meaning that they perceived research use as important because it was connected to other important values and needs. They believed that research use ensured that patients received the best possible care. Research use also facilitated their personal growth and professional development. For some physiotherapists, the use of research in their clinical practice 
was based on identified motivation. They identified the personal value of research use and considered it to be beneficial to achieve desired goals, such as facilitating an improved status of the physiotherapy profession, career advancement and collaboration with other health professionals.

Research use was characterized by introjected regulation for other physiotherapists who used research because they felt it was expected by patients. These physiotherapists put pressure on themselves to use research, partly to avoid negative feelings such as inadequacy or worry. There were also physiotherapists who used research somewhat reluctantly because they felt it was required or even demanded by leaders and authorities; research use for them was externally regulated. They felt they were under pressure to validate their work by using research, but they did so primarily to satisfy external demands from "above" (i.e. managers, county councils and health authorities). One physiotherapist expressed amotivation in relation to research use, as this person did not believe that the effort of keeping up to date with research would yield a desired outcome. The person was simply uninterested and considered research to be "boring".

\subsection{Study II}

Study II explored conditions that are supportive of physiotherapists' use of research use in their clinical practice. The following research question was addressed:

- What conditions at different system levels are supportive of physiotherapists' research use in clinical practice?

The study identified nine types of favourable conditions for physiotherapists' research use in clinical practice. These conditions existed at three system levels: the individual (two types of conditions), workplace (four conditions) and extra-organizational levels (three conditions).

The study identified two favourable individual-level conditions. Having positive attitudes to research and a strong motivation to use research in clinical practice were believed to be conducive to research use. The physiotherapists also thought various research-related knowledge and skills were helpful to 
apply research in clinical practice. Critical or analytical thinking facilitated critical appraisal of research studies to determine, for instance, the strength of evidence and whether findings were feasible in routine practice.

Four types of workplace-level conditions were found to be favourable to research use. Leadership played an important role in enabling research use. Many physiotherapists emphasized the importance of active encouragement from their managers. However, the degree to which managers actually supported research use seemed to vary a great deal. As well as informal encouragement or support, the physiotherapists also pointed to the importance of formal and explicit management decisions on the desirability of using research in clinical practice. They believed that an organizational culture that supports learning and competence in development activities provides favourable circumstances for research use. The physiotherapists mentioned several types of resources that facilitated research use, including access to research, financial and personnel resources to provide opportunities to participate in researchinformed courses and conferences and to conduct research and development projects. Further, they identified time as an important resource that affected their ability to apply research findings in clinical practice. The physiotherapists described several forms of knowledge exchange that they believed supported their research use. Knowledge exchange with clinicians from other professions was also mentioned as an enabling factor for research use, as was knowledge exchange that occurred with patients who might have complex problems or are inquisitive.

Three favourable conditions at the extra-organizational level were identified. Evidence-based guidelines that can be used to assist decisions about appropriate treatment were considered helpful for research use. The physiotherapists believed guidelines provide a benchmark from which to start when considering different treatment options. Most of the physiotherapists attended external meetings and/or took part in research-related networks and conferences. This exchange of knowledge and experience with other physiotherapists was considered to be very important for development of competence and commitment to using research. Involvement in academic research and education was also conducive to research use. Several physiotherapists collaborated with researchers and teachers from nearby universities. Some of the physiotherapists were also engaged in teaching activities and participated in developing curricula for physiotherapy courses. They thought this sort of interaction and in- 
volvement contributed positively to their interest in keeping up to date on research and using research as part of their daily practice.

\subsection{Study III}

Study III explored the individual and organizational learning that occurs when physiotherapists participate in a research project. The study addressed this research question:

- What do physiotherapists learn through participation in a research project relevant to their professional development and to what extent is this learning transferred to their colleagues and the wider organization?

The physiotherapists mentioned that several of the treatment techniques applied in the research project was exercises that they had actually learned as part of their physiotherapy education, but had since forgotten about. Participation in the project thus contributed to improved understanding of how to apply knowledge they already had. The physiotherapists experienced involvement in the research project as an opportunity to learn more and become more skilful concerning whiplash disorders (i.e. the specific problem being investigated in the study). They felt their participation broadened their treatment technique skills and believed their learning benefited not only the patients involved in the intervention study but also other patients who did not take part in the study.

The physiotherapists also described learning in terms of obtaining a better understanding of neck problems generally and whiplash disorders specifically. Some physiotherapists believed their participation enabled them to question some of their current practices. They mentioned that participation in the project also increased their motivation for their job and improved self-confidence and self-efficacy in their professional role. They believed their participation in the research project contributed to making their practice more researchinformed. Participation triggered interest in and positive attitudes to research and fostered improved understanding of the research process and the challenges involved in conducting research. 
Many physiotherapists stated that they discussed and shared learning experiences from their participation in the research project with colleagues who were not involved in the study. Some mentioned that sharing knowledge was well integrated in their everyday work at their clinic. The physiotherapists typically attended meetings devoted to knowledge and experience exchange, but many complained that they had not been able to transfer learning from the research project at such meetings. They also brought up time pressures, which restricted their opportunity to transfer knowledge to colleagues and the wider organization. Regardless, some physiotherapists believed participation in the research project contributed to creating a more research-informed culture in their clinic by means of their discussions and reflection with colleagues.

\subsection{Study IV}

This study explored how physiotherapy leaders can contribute to developing a culture that is conducive to implementation of EBP in physiotherapy by communicating their values, norms and assumptions to followers. The study addressed this research question:

- How do physiotherapy leaders influence the culture for the implementation of evidence-based physiotherapy practice?

The leaders' descriptions of the extent to which EBP-related activities and issues are given attention, measured and controlled suggested that this embedding mechanism contributes towards creating a more EBP-informed culture. The leaders observed that there are increasing demands for physiotherapy and health care in general to be underpinned by research and for decisions to be based on evidence of their effectiveness, which means that EBP issues cannot be ignored. The leaders highlighted the importance of discussing and planning EBP-related activities with physiotherapists in the clinics. They commented that a great deal of emphasis was put on using guidelines produced by the National Board of Health and Welfare.

Deliberate role modelling, teaching and coaching were also applied as mechanisms to achieve a more EBP-informed culture. Many of the leaders took their role as EBP leaders seriously and were anxious to support various EBP-related activities despite resource constraints. They stressed that they as leaders need to be knowledgeable on EBP issues to be able to supervise and support their 
subordinates in their efforts. EBP-related knowledge and expertise differed among the leaders, influencing their ability to function as EBP leaders.

Concerning allocation of rewards and status, the leaders described various means by which EBP expertise was valued. Most leaders created a special status for physiotherapists with more extensive education, training or continuing professional education. Some reported that they take EBP competencies and involvement in EBP-related issues into account in their staff appraisals. They mentioned that clinics that conduct research and pursue EBP-related activities were recognized by the higher management levels.

The leaders believed that allocation of resources earmarked for EBP-related activities were insufficient. They remarked that financial and budgetary issues were prioritized by managers at the higher levels in the county councils. Resources were also described in terms of EBP-relevant competencies, i.e. more intangible resources. Training on improving EBP skills and time set aside for knowledge exchange on research matters in the clinics were two ways of providing resources to benefit a more EBP-informed culture.

With regard to recruitment, selection, promotion and communication, the leaders described the importance of building capacity for EBP by appointing some physiotherapists to a special role with responsibility for EBP issues in the clinic. They were often highly motivated to keep up to date on physiotherapy research and support implementation of EBP in the clinic. The leaders also emphasized the importance of recruiting new young physiotherapists because they are often competent in EBP issues.

The embedding mechanism of reaction to incidents and crises largely lacked relevance with regard to fostering a more EBP-informed culture. The leaders recognized challenges in obtaining support for EBP-related activities from higher management levels in times of organizational stress in the clinics or in the county council as a whole.

Few of the secondary embedding mechanisms had much relevance with regard to influencing or reinforcing an EBP-informed culture. The organizational design, structure, systems and procedures did not appear to be particularly conducive to EBP and the leaders did not mention any specific rites or rituals in their organizations that were relevant to EBP issues. Furthermore, there were no obvious links between EBP issues and the design of the physical 
space, facades and buildings. Also, the leaders did not relate any stories about important events and people that seemed to be related to EBP-related activities. The leaders could, however, provide a few examples of formal statements concerning EBP issues. The county councils reported on various EBP-related activities in their annual reports but the extent to which this was done varied greatly. Scientific publications and the number of staff with $\mathrm{PhD}$ degrees or professor titles were often reported but less focus was placed on what improvements were achieved or the extent to which research was integrated into routine practice to improve the work of the clinics. 


\section{DISCUSSION}

This chapter discusses the results and implications from the four studies of this thesis. Key research findings and implications of the findings are presented first. The premise behind the multi-level approach to the study of implementation of EBP in physiotherapy is described. The different levels explored in the four studies are discussed, before the levels are put together for a discussion of their interdependence and "relative" importance. After some concluding remarks on EBP, methodological considerations are addressed. The chapter finishes with the conclusions and some thoughts concerning future research.

\subsection{Key research findings}

The four studies of this thesis sought to explore conditions at different levels, from the individual level to the organizational level and beyond, for the use of research and implementation of an evidence-based physiotherapy practice.

Study I investigated the motivations behind physiotherapists' use of research in clinical practice. The study identified a broad range of motivations underlying their research use. Most physiotherapists expressed autonomous forms of motivation for research use, but there were also physiotherapists who exhibited controlled motivation or completely lacked interest in research (i.e. amotivation).

The findings of Study I suggest that educational programs for EBP may benefit from being tailored to account for differences in motivation among the participants. The study findings also point to the possibility of using autonomously motivated physiotherapists as change agents to create favourable conditions that encourage autonomous motivation by way of feelings of competence, autonomy and a sense of relatedness.

Study II explored conditions that are supportive of physiotherapists' research use in their clinical practice. The study identified nine factors at three interdependent system levels that physiotherapists in Sweden perceived to support 
their use of research: the individual level, the workplace level and extraorganizational level. Research use in physiotherapy appears to be an interactive and interpretative social process that involves considerable interaction with various people, both internal and external to the workplace.

The findings of Study II underscore that interventions to achieve more EBP in physiotherapy through increased use of research in clinical practice must account for a complex interplay between interdependent multiple-level factors. Interventions directed at individual physiotherapists' skills, knowledge, attitudes and motivation concerning research use should be considered in a wider context of influences on clinical behaviour. Individually oriented initiatives for increased research use could benefit from being supported by facilitating organizational structures and processes because there is a dynamic interplay between the individual level and the workplace level.

Study III explored the individual and organizational learning that occurred when physiotherapists participate in a research project. It was found that the physiotherapists' participation yielded many individual learning experiences. Participation fostered positive attitudes to research and was conducive to achieving a more research-informed physiotherapy practice. Participation was associated with a deeper understanding of the challenges involved in conducting research. However, the study also showed that organizational learning due to the research project was limited because individual learning was hardly transferred to the wider organization. There was a paucity of formal learning opportunities at which knowledge could be shared, which meant that learning tended to be informal.

The findings of Study III point to collaboration between practitioners and researchers as being potentially beneficial for both practitioners and researchers. The study also highlights the need for more formal forums where practitioners can share learning experiences gained in research project participation to allow for organizational learning. These forums should be further supported by facilitating organizational structures and processes for the uptake of individual learning at group and organizational learning levels.

Study IV explored how physiotherapy leaders can contribute to developing a culture that is conducive to implementation of an evidence-based physiotherapy practice by communicating their values, norms and assumptions to followers. The study suggested that most of the embedding mechanisms de- 
scribed in the applied framework by Schein (2010) for influencing or reinforcing an EBP-informed culture had limited relevance. The mechanisms of giving attention to, measuring and controlling on a regular basis as well as deliberate role modelling, teaching and coaching did have some relevance. However, EBP issues seemed to depend on committed individuals, often younger physiotherapists, who were interested in research.

The findings of Study IV indicate that leaders represent an unfulfilled potential in influencing the culture for achieving a more evidence-based physiotherapy practice. Given these potential, educational strategies in topics such as change management and implementation used in conjunction with interventions aimed to implement EBP, i.e. a specific treatment method, guideline or new routines, might be beneficial, but changing the culture for EBP is not easily accomplished.

\subsection{A multi-level approach}

The four studies of the thesis have addressed conditions for research use and implementation of EBP in physiotherapy at multiple levels. Table 3 shows the focus of each of the four studies of the thesis. It should be noted that it is a simplification to describe just these three levels; many more could be identified. The different "levels" should be seen as a continuum rather than distinct analytical units.

Table 3: The different levels addressed in the four studies of the thesis.

\begin{tabular}{cccc}
\hline Study & $\begin{array}{c}\text { Individual-level } \\
\text { conditions }\end{array}$ & $\begin{array}{c}\text { Workplace/ } \\
\text { organizational } \\
\text { conditions }\end{array}$ & $\begin{array}{c}\text { Extra- } \\
\text { organizational } \\
\text { conditions }\end{array}$ \\
\hline I & $\mathrm{X}$ & & \\
II & $\mathrm{X}$ & $\mathrm{X}$ & $\mathrm{X}$ \\
III & $\mathrm{X}$ & $\mathrm{X}$ & \\
IV & & $\mathrm{X}$ & \\
\hline
\end{tabular}

An important departure point for this thesis was that it is not sufficient to focus solely on individual conditions or organizational conditions or extra- 
organizational conditions in order to provide a holistic understanding of the complex phenomenon of implementation. Rather, all levels must be addressed, even if that means increased complexity in terms of the research conducted. For example, an organization is not simply the sum of its individuals. Indeed, "aggregating" the findings measured or studied at the individual level to the collective level represents a sort of ecological fallacy, i.e. drawing conclusions about groups or collectives based only on the analysis of individual data. Therefore, each level cannot be investigated on its own, in isolation, if the ambition is to obtain a full picture. A system can be understood only as an integrated whole, and it is not only composed of the sum of its components. A system also concerns the relationships among those components (Strati, 2000).

Factors influencing the implementation of EBP in health care are often assessed individually in implementation studies (implicitly) assuming a linear relationship between the determinants and the outcomes and ignoring that individual barriers and enablers may interact in various ways that can be difficult to predict. For instance, there could be synergistic effects such that two seemingly minor barriers constitute an important obstacle to successful outcomes if they interact. Another issue is whether all relevant barriers and enablers are examined in these studies, which are often based on survey questionnaires (Nilsen, 2015).

It has become more widely recognized that a systems perspective encompassing conditions and influences at different levels, from the individual practitioner to society as a whole, is required to provide understanding and explanation of implementation processes and outcomes (Holmes et al., 2012). Early research on implementation of EBP in various health care contexts tended to focus on individual practitioners. After all, it is usually the individual physiotherapist who ultimately decides whether or not to perform a specific clinical practice such as a treatment method, yet they do not exist in a vacuum and their decisions are influenced by colleagues, managers and many other factors, which are considered part of the context in implementation science. Indeed, practitioners' favourable beliefs, attitudes and motivation concerning research use might be difficult to "convert" into regular practice if colleagues, leaders and various resources do not provide facilitating contextual conditions.

The systems perspective, with different levels of implementation influences, suggests that different types of theories might be needed to understand and explain implementation processes and outcomes. This was an important prem- 
ise for the studies of this thesis, in which different theories were applied. Theories concerning individuals' behaviours are not the same as those that might contribute to an understanding of the influences at group or organizational level on implementation. Implementation science borrows and applies theories from many different disciplines. There is no single "grand implementation theory" because implementation is widely considered to be too multifaceted and complex as a phenomenon to allow for universal explanations (Nilsen, 2015). Rather, many different theories are relevant for understanding and explaining the many aspects of implementation of EBP.

\subsection{Individual-level conditions}

Study I showed that research use for some physiotherapists was intrinsically motivated, i.e. these individuals were driven by a genuine curiosity and willingness to learn. This suggests the relevance of a "user-pull" approach to research use, i.e. a process driven by health care professionals' own motivation to learn and develop (Nutley et al., 2007). Implementation is more often described in "producer-push" or top-down terms, with research-based knowledge such as guidelines being disseminated by authorities. However, external expectations or pressure for practitioners to use research and adhere to clinical guidelines are likely to yield more externally regulated motivation. Herscovitch and Meyer (2002) found that commitment to implement organizational change based on "want to" motives reflected the highest level of commitment.

The most motivated physiotherapists can be assumed to be early adopters in Rogers' classic taxonomy of different innovation adopters as part of his Theory of Diffusion (Rogers, 2005). Early adopters often have the status and authority to act as change agents in their organization; the intrinsically motivated physiotherapists in Study I might be used as change agents. Furthermore, local opinion leaders are seen to have a great influence over their peers in social networks and influence theories; this has also been confirmed in earlier research (Grimshaw et al., 2006; Stross, 1996). However, strategies to implement EBP that focus on the individual's influence on change or changing one's behaviour might not be effective unless there is contextual support from leaders, resources, strategies and structures. 
The physiotherapists in Study II believed that positive attitudes to research provided favourable conditions for research use in clinical practice. However, a cognitive understanding and positive attitudes towards the use of research do not necessarily generate positive or intrinsic motivation. Although attitude is generally considered to be an important predictor of behaviour (or behaviour change), research in many fields has documented that the progression from positive attitudes to desired behaviours tends to be complex Verplanken et al., 1998) Difficulties in translating positive attitudes to using research in clinical practice have been noted among health care professions (Squires et al., 2011).

Study III showed that involvement in a research project increased the physiotherapists' self-confidence, positively influenced their attitudes to research and yielded many individual learning experiences that might be beneficial to achieve a more evidence-based practice. Increased feelings of competence and confidence are assumed to foster more autonomous forms of motivation (Deci and Ryan, 1985; Ryan and Deci, 2000). Furthermore, low confidence in one's capabilities to perform a behaviour that is unfamiliar can impair the motivation to perform the behaviour (Bandura, 1997).

Leaders in Study IV often relied on physiotherapists who kept up to date with and informed colleagues about the latest physiotherapy research findings. These physiotherapists usually took a personal interest in research and development issues, which means they were highly motivated. However, delegating much of the responsibility for implementation of EBP to individual physiotherapists means that EBP issues become less of a collective or leadership responsibility. These dedicated individuals effectively functioned as champions for EBP as they were expected to facilitate and promote EBP in the clinics.

Rogers' Theory of Diffusion (Rogers, 2005) highlights the importance of intermediary actors such as opinion leaders and change agents for successful adoption and implementation of innovations. Similar roles are described in numerous implementation science frameworks and models. Having champions of EBP has been shown to be important for implementation of EBP in various settings (Greenhalgh et al., 2005; Rycroft-Malone, 2010; Stetler, 2010; Stevens, 2013), however it can also be disadvantageous to become too dependent on individuals because sustainability of EBP may be compromised if these individuals tire or take up other job opportunities (Titler et al., 1995; Rubin et al., 2005; Brownson et al., 2012). 


\subsection{Contextual conditions (workplace, organi- zational and extra-organizational levels)}

The context of implementation of EBP represents the levels "above" the individual level, i.e. the workplace, organizational and extra-organizational levels, which were addressed in Studies II, III and IV. The context concept lacks a unifying definition in implementation science (and other fields such as organizational behaviour). However, the context is generally understood as the conditions or surroundings in which something exists or occurs, typically referring to an analytical unit that is higher than the phenomena directly under investigation (Johns, 2013; Nilsen, 2015). The context may also have relevance in Study I because it is likely that the motivation among the physiotherapists was influenced by the context.

The context has been described as "an important but poorly understood mediator of change and innovation in health care organizations" (Dopson et al., 2005; Ashton et al., 2007; Mohr et al., 2008; Scott et al., 2008). In implementation science, contextual features are typically described as determinants for implementation of EBP alongside others such as the characteristics of the implementation object (e.g. a new treatment method) and the effectiveness of the implementation strategies that are used to facilitate implementation (e.g. a course or clinical guidelines). The inner context and outer context are often described as distinct concepts; the former includes the features of the workplace or organization in which implementation takes place, whereas the latter relates to the extra-organizational, wider environment within which health care organizations reside (Nilsen et al., 2013). The context is an integral part of many frameworks and models used in implementation science such as Promoting Action on Research Implementation in Health Services (PARIHS) (Kitson et al., 1998; Rycroft-Malone, 2010), the Conceptual Model (Greenhalgh et al., 2005) and the Ottawa model (Logan and Graham, 1998).

There is increasing interest among implementation researchers in using theories concerning the context of implementation because this concept is becoming more widely acknowledged as having an important influence on implementation outcomes (Nilsen, 2015). Physiotherapists work in the context of health care, which includes different professional categories and numerous subspecialties within medicine that often work in teams. Pettigrew et al. (1992) argue that teams represent a potential lever for change and are to be seen as 
building blocks of a microsystem (Ferlie and Shortell, 2001). A microsystem contains human, financial and technological resources to perform its work (Quinn, 1992). There is research that point towards the positive relationship between functioning teams/microsystems and higher quality of care (Aiken et al., 1997; Mitchell et al., 1996).

Studies II, III and IV all demonstrated the importance of the organizational culture. The importance of the culture within organizations for learning is well known and has been the focus of research in many fields, but has increasingly been recognized in implementation science (Nilsen, 2015). To some extent, the studies drew on a simplified concept of culture because they did not differentiate between different types of culture, i.e. subcultures, within physiotherapy or health care. It is well known that health care organizations consist of multiple cultures rather than just one due to the variety of professionals, teams and divisions that operate in the organization (Ferlie and Shortell, 2001). A subculture has its own specific perceptions of reality and sets norms and values. Professional subcultures tend to be strong as described in the introduction on the history of physiotherapy. For example, physiotherapists operate in a clinical culture making decisions based on medical knowledge. The relationship with the patient is based on a direct cause-effect within quiet short time-frames. As a contrast, managerial culture has its knowledge base in behavioural science, the cause-effect relationship is not obvious, the time horizon is longer due to planning and the focus is the clinic, team and patient groups (Ferlie and Shortell, 2001). Furthermore, this cultural divide also exists exists between and within medical and health professions (Ferlie and Shortell, 2001).

Studies II and IV identified a number of workplace and organizational conditions that influence the use of research in daily practice, including the support of leaders, communication, resources, access to knowledge, structure, organizational culture and values about the outcomes of EBP. All conditions can be interpreted in different ways depending on by whom and in what situation the conditions are described and used. For example, almost all physiotherapists in Study II mentioned leadership as a condition that might facilitate EBP. However, what aspect of leadership or leadership style that is highlighted as a facilitator for EBP depends on the situation and context. Thus, it is important to note that the conditions found in the studies are not fully generalizable because they might differ and are determined by the situation. Thus, the conditions found in this thesis are to be regarded on a conceptual level. 
The leadership for implementation of EBP was in focus in Study IV. Leaders in this study who worked more strategically towards creating an EBP-informed culture exhibited qualities that are characteristic of a transformational leadership style (Yukl, 2006). Transformational leaders stimulate followers to transcend their own immediate self-interest for the greater good of a group or organization. Earlier research has demonstrated the importance of transformational leadership for organizational performance (Howell and Avolio, 1993; Yammarino et al., 1993; Bass, 1985; Bass and Avolio, 1997; Yukl, 2006) and a climate of organizational innovation (Sarros et al., 2008). Furthermore, Damanpour and Schneider (2006) have emphasized the importance of a visionary leader to create a culture of change that assists adoption of innovations.

Although the results from Study IV showed that the leaders had a modest impact on the EBP culture, there are other studies that support a link between leadership and culture that is adaptive to change (Ostroff et al., 2003; Denison, 1990), and the relationship between transformational leadership and innovation (Ogbonna and Harris, 2000; Xenikou and Simosi, 2006; Jassawalla and Sashittal, 2002; Prather and Thurell, 2002). Practitioners in health care often become managers as a means of career development. However, due to their professional background (e.g. being trained in medicine), their skills and capabilities in issues such as change management and implementation are limited, as noted in Study IV. Capacity building in terms of education and training for managers in implementation and change management to allow them to become confident in supporting their teams during changes would be important for health care organizations who strive to become more research informed.

Studies II and III found that discussions and reflection with colleagues facilitate and contribute to a more EBP-informed culture. This microsystem level comes between the individual level and the workplace or organization level. Sharing experience and knowledge is important for team learning and the use of EBP, but it should not be taken for granted that all practitioners are willing to share their knowledge. Some studies have concluded that specific personality traits are associated with more positive attitudes to knowledge sharing (Cabrera and Cabrera, 2005; Mooradian et al., 2006). Personalities that are characterized by an "openness to change" have a positive attitude to sharing knowledge (Cabera and Cabrera, 2005). The physiotherapists in Study III implied that knowledge sharing that is integrated into their workplace culture 
provides a favourable condition for organizational learning. Similar sentiments were expressed by the leaders in Study IV.

The extra-organizational level is affected by societal decisions and changes that might affect the visions, goals and content of the health care system. The studies explored the importance of this level only to a small degree, although Study II found that guidelines could assist decisions about appropriate treatment and are supportive of research use.

\subsection{Putting the levels together}

Taken together, the four studies of this thesis emphasize the utmost relevance of contextual conditions (i.e. the levels "above" the individual) for research use and implementation of EBP in physiotherapy. The studies also indicate that the levels are dynamically interrelated, meaning that changes at one level will likely affect the status at other levels. Researchers such as Cappelli and Sherer (1991) and Mowday and Sutton (1993) have stressed that context operates across different levels and the analysis of variables at one level affects variables at another level. Thompson (1970; page 60) explained this interdependence in the following way: "The whole is created by a 'set of interdependent parts and each contributes something and receives something from the whole, which in turn is interdependent with some larger environment."

The system levels are responsive to one another and can challenge each other and/or search for consensus and ways to understand and develop together. Furthermore, changes can occur within the existing context, e.g. a given set of norms and values, adding to the prevalent knowledge. The new method or way to do things may not be antagonistic towards the traditional ones; it can simply be different. Gagliardi (1986) argues that change is more likely to be accepted and realized if the basic values are not disowned by the change; then it can rather be accepted as broadening the organizations options (Gagliardi, 1986). Alternatively, the change can challenge prevalent assumptions and represent a break with existing truths, which is more revolutionary and harder to accept. This can be referred to as "second-order change" (Watzlawick et al., 1974) or "double-loop learning" (Argyris, 1976).

What level or levels exert the strongest influence on implementation of EBP in physiotherapy? This question cannot be answered on the basis of this thesis, 
for several reasons. The studies were not designed to be intervention studies to influence the "degree" of EBP implementation or research use. There was no attempt to capture causal mechanisms or measure the "strength" of the influences of the various levels on EBP implementation. However, this question can be addressed with reference to the concept of situational strength. Socalled strong situations constrain options and provide clear signals about what is expected of individuals. An example might be a pervasive team or organizational culture, with shared norms, values, assumptions and perceptions strongly influencing the behaviours among the individuals in this particular team or organization. Strong situations "lead everyone to construe particular events the same way, induce uniform expectancies regarding the most appropriate response pattern, provide adequate incentives for the performance of that response pattern and require skills that everyone has to the same extent" (Mischel, 1977, page 347). Strong organizational cultures tend to act as a form of social control that increases behavioural consistency. Conversely, weak situations do not generate uniform expectancies concerning desired behaviours (Cooper and Withey, 2009). The findings of Study I, with physiotherapists expressing a wide range of reasons for using research in their clinical practice, and the results from Study IV suggest that the culture for implementation of EBP in physiotherapy is still rather weak, meaning that implementation of EBP in physiotherapy represents a weak situation, with a large degree of individual "freedom" to use research.

\subsection{Some reflections on evidence-based prac- tice in physiotherapy}

The concept of EBP has assumed a central position in physiotherapy and other professions in health care and beyond. There is increasing emphasis on practitioners in physiotherapy and other areas of professional practice to acquire EBP skills and become research literate, so that they can apply, read and even conduct research themselves. The argument that scientific evidence should be used to guide clinical decisions has an instant intuitive appeal and the underlying rationale is difficult to question. Few of us want to be seen as "antiscientific". Hence, we implicitly assume that EBP is something important to strive for. 
The paradigm of EBM and EBP presumes that practitioners always act in a rational manner to balance the advantages, disadvantages and are fully informed of alternatives when making a decision. This assumption has its origin in cognitive theories but is challenged by more descriptive theories that assume a cognitive-psychological perspective. This perspective has its origin in education and suggests that decisions may not always be rational, instead being made up of the practitioner's previous experiences (stored knowledge from earlier patient cases) and contextual influences such as colleagues' opinions or time available (Grol et al., 2004). Furthermore, social network and social influence theories focus on the ties, relations and influences from values and norms in the social network of professionals when making a decision.

The concept of EBP is interpretive and can be understood in different ways by different actors in an organization, e.g. physiotherapists, other professions and managers. Furthermore, these actors may emphasize different aspects of the tripartite definition of the EBP concept (i.e. clinical experience, patient preferences and research evidence) that they find to be most important or attractive. This implies that EBP will be applied differently among actors and among and within organizations. This adds complexity to the concept of EBP. Although definitions exist regarding the meaning or content of EBP, these may not be widely known or "adhered" to among different actors. Perhaps the concept of EBP should first and foremost be seen as an ideal to strive for like other normative ideals, such as ethics or a "learning organization." There will always exist some contradictions and/or tensions concerning the relationship between best practice (standardization) and best fit (situational).

\subsection{Methodological considerations}

In social science, finding one truth is seldom the main purpose and not even considered possible. Knowledge is not objective because it is always coloured by interest, values, time and space. Knowledge is dynamic and changed or modified over time. If all knowledge were static, there would be no need to work with continuous improvement or be concerned about updating our methods, and my thesis' research questions would not need answers. The studies in this thesis involve material from focus group and individual interviews with physiotherapists and managers within physiotherapy. Together the studies allow for an in-depth analysis of conditions concerning the use of research in physiotherapy practice. 
Being strictly objective in social science research is very challenging. Still, it is the researcher's task to separate scientific knowledge from common sense knowledge through accurate research methods and self-reflexive communication. We all have some presuppositions about the world around us; we continuously construct meaning in objects and in people's actions. Furthermore, to not construct or create meaning is also a way to value and relate to things in the world (Patton, 2002).

Concepts that are used to assess research quality, i.e. validity, reliability and generalization, might be inappropriate in a more interpretivist research context (Johnson and Duberley, 2000). These concepts have their origin in the positivistic research tradition. However, quality assessment is equally important regardless of the research paradigm or if the research results are based on quantitative or qualitative methods. Qualitative research often applies the concept of trustworthiness to consider what valid knowledge is. Trustworthiness encompasses four criteria that also have their equivalents in quantitative research: credibility (internal validity); transferability (external validity); dependability (reliability); and confirmability (objectivity) (Lincoln and Guba, 1985; Bryman, 2001).

Transferability concerns the generalization of the results to other contexts and settings and whether physiotherapists other than those included in the studies might share the same experiences. Qualitative research typically entails the study of small groups sharing their experiences of the phenomenon under investigation and focuses on depth rather than breadth. However, the studies all have respondents from different settings, geographic locations, age, sex and experience to include a breadth of views and experiences. Whether these findings hold in some other context or in the same context at some other time is an empirical issue. However, there is no reason to assume that the experiences of the respondents in these studies are unique and not transferable to other Swedish physiotherapists and contexts. Furthermore, to contrast my results to similar studies in the research field might also strengthen the transferability. However, one needs to be careful not to neglect the accuracy of the findings even if they do not correspond with other research results. If conflicting findings or anomalies are never regarded, there would never be any paradigm shifts in the sense of Kuhn. Confirmability refers to the degree to which the results are supported by the gathered data and that the researcher has been reflective regarding his or her own values in the interpretations. Here, all the 
results from the studies were discussed with physiotherapists in seminars and/or with co-authors to elucidate the confirmability of the findings.

Dependability concerns the quality of the whole research process and the use of appropriate research methods. Lincoln and Guba (1985) argue for the researcher to have an auditing approach alongside all the steps in the study. Furthermore, credibility concerns whether the research findings represent a credible analysis of the material but also that the research is carried out in good practice. These two criteria are strengthened if all planning and methodological considerations in all studies have been discussed and scrutinized in seminars with researchers from different disciplines. Furthermore, the authors of the papers have continuously discussed and audited the research process to ensure transparency and quality.

The studies in this thesis all have shortcomings that must be considered when interpreting the specific and overall findings. The studies were set in Sweden and the transferability of the findings beyond the context of the Swedish health care system might be limited. Physiotherapists in Sweden are highly autonomous, which is not the case in all countries. The focus group and individual interviews may not have been fully representative of the different types of physiotherapists or settings in Sweden although heterogeneous purposeful samples were always sought. The leaders interviewed were managers at the middle level of county councils and managers are not necessarily leaders, although the roles of leaders and managers overlap.

\subsection{Conclusions}

The findings from the studies support a number of conclusions with regard to the four research questions posed. From Study I, it can be concluded that many different types of motivation underlie physiotherapists' use of research in their clinical practice. The type of motivation ranges from so-called amotivation, i.e. a lack of intention to engage in research use, to intrinsic motivation, which means that research use is perceived to be interesting and satisfying in itself. Most physiotherapists tend to express autonomous forms of motivation for research use, generally viewing research use in favourable terms.

Conclusions drawn from Study II are that there are numerous conditions at different levels that can provide support for physiotherapists' use of research 
in their clinical practice. Favourable individual-level conditions include positive attitudes and motivation concerning research use and research-related knowledge and skills. Workplace-level conditions that are conducive to research use include formal and informal leadership support, an organizational culture that fosters learning and competence development, research-related resources such as access to research and time, and knowledge exchange with other clinicians and patients. Conditions at the extra-organizational level that are conducive to research use include EBP guidelines, involvement in external meetings, networks and conferences as well as involvement in research and education.

Study III arrived at the conclusion that physiotherapists' participation in a research project can yield many individual learning experiences, including fostering improved understanding of the research process and the challenges involved in conducting research. Research participation can also trigger interest in and foster positive attitudes to research, something that might contribute to achieving a more research-informed physiotherapy practice. However, the study also concludes that organizational learning is limited because individual learning is not sufficiently transferred to the wider organization. A paucity of formal learning opportunities at which knowledge can be shared suggests that learning tends to be informal.

Study IV concludes that physiotherapy leaders in Sweden appear to contribute to a modest degree to establishing a culture that is conducive to implementing EBP in physiotherapy practice. Instead, EBP issues largely seem to depend on committed individual physiotherapists who keep to up to date with research in physiotherapy and inform colleagues about the latest research findings. However, delegating much of the responsibility for implementation of EBP to individual physiotherapists suggests that EBP issues become less of a collective or leadership responsibility in physiotherapy.

\subsection{Future research}

The results of the studies in this thesis have provided new insights on the implementation of EBP in physiotherapy. The studies suggest several important areas for future investigation concerning EBP and research use in physiotherapy as well as in health care in general. A few issues and areas of research that 
I believe would benefit from further exploration and investigation include the following.

One of the studies concerned leadership in relation to implementation of EBP in physiotherapy. I believe the importance and role of leadership for successful implementation of EBP and research use warrants further research because there are many unanswered questions. Implementation science has merely scratched the surface of this crucial topic. There are many questions that need to be addressed. How can managers and leaders be supported and support health care organizations and units through routines, processes and behaviours pertaining to research use? Many health care managers and leaders have their professional origin in health-related disciplines such as medicine, nursing, physiotherapy, etc., which means that they might lack relevant knowledge regarding issues such as implementation, change management and organizational development. What competencies are required to facilitate implementation? Another question is to what extent health care managers are also leaders (because managers might not necessarily be leaders) with regard to implementation issues? It would be of interest to conduct educational interventions with the aim of teaching and developing the competencies necessary to support implementation of EBP. To what extent could such interventions improve implementation and facilitate the change required? Intervention studies involving leaders/managers are rare in comparison with studies that focus on "frontline" health care practitioners.

Culture is another area that I believe deserves more attention in implementation science. Leadership and culture are interrelated because leaders are in a position to influence the members of an organization, unit, profession (or other collectives of individuals), while the culture simultaneously influences who become leaders. Ultimately, attaining a more evidence-based health care requires an "EBP culture" such that the shared norms, values, expectations and assumptions make it natural and instinctive to seek out, critique and integrate research into everyday clinical practice (i.e. applying the steps of the EBP decision-making process) as well as to learn and apply new interventions, methods, programmes, etc., that have sufficient empirical support (i.e. use evidence-based practices). Clearly, research use is an interactive and interpretative social process that involves a great deal of interaction among various people, groups, organizations and society at large; it is not merely an individual process. Much implementation research thus far has focused on individuals, but there is a need for research conducted at the collective or organizational 
levels of health care. My impression is that implementation "in practice" often is concerned with a specific intervention such as a diagnostic or treatment method that health care practitioners are expected to apply or EBP is seen as a time-limited "project" that is carried out for a certain time (and then laid to rest when other projects are initiated). However, I think implementation of EBP should be viewed in terms of striving for a culture that permeates the entire organization and its members. Many questions could be addressed in order to understand if and how such a culture can be influenced and established. For example, to what extent is it possible to create knowledge management systems that facilitate a learning organization with regard to EBP issues? Building on one of the studies in this thesis, it would be interesting to investigate further to what extent leaders can influence the culture for EBP in different settings. What characterizes cultures that are more conducive to EBP? Cultural studies of EBP implementation are still rare, but I believe this is an area where more work is needed.

A third area where I see the need for further research is collaboration and interaction between researchers and health care practitioners. Interactive approaches to implementation of EBP would be one way to strengthen the links between the research and practice communities; this could have a positive impact on research use in physiotherapy and other areas of health care. One of the studies touched on this, but I have not come across many studies that have addressed this issue. I think collaboration could encourage a two-way flow of information and influence: practitioners can gain a better understanding and insights into research-relevant issues, while researchers are better able to orient their studies to the needs and interests of practitioners. This approach to facilitating a more EBP in physiotherapy has not received much research attention, but I think researcher/practitioner partnerships and collaborations are important to explore further.

Thus far, issues concerning leadership, organization and potential learning through collaboration have not attracted much interest from the implementation science community. A likely reason for this is the fact that research on EBP implementation emerged from health-related research, in the wake of the spread of the evidence-based model. However, I believe more of a social science perspective on implementation of EBP is required because research use, regardless of the practice setting, is clearly a highly complex multi-level social process. Hopefully, the type of research I envision will be funded and expanded in the future, for I believe it is important for a broader and deeper under- 
standing of the challenges involved in implementing EBP in physiotherapy and other areas of health care. 


\section{POSTFACE}

Science is not only a disciple of reason but, also, one of romance and passion. - Stephen Hawking

In 2010 I had the privilege to be accepted as a $\mathrm{PhD}$ candidate and start the journey to write a doctoral thesis. Conducting the studies and assembling the thesis have been great fun, but also hard work. I do like the research process though! To conduct research requires creativity, curiosity and questioning, but one must also relate and adhere to rules. I guess that most people who know me, including my supervisors, would say that creativity is more "me" than following rules. However, Einstein said that "the true sign of intelligence is not knowledge but imagination".

First and foremost I want to thank my supervisor Per Nilsen. You have supported me $100 \%$ and have never tried to inhibit my ideas but given me freedom and space. You have always responded quickly to all my questions, showing no signs of frustration. We share an interest in challenging the takenfor-granted and exploring new ground. This has made our collaboration very creative. Your commitment to my research project and your competence in implementation science is deeply impressive.

And I also want to thank Anneli Peolsson, my co-supervisor for always being positive and guiding me in the world of physiotherapy, which was completely foreign territory when I embarked on this journey, five years ago. You have shared knowledge that has been very important.

Sincere Thanks to all my participants in my studies for taking your time to share your experience and knowledge with me. Without you there would be no thesis.

I would also like to thank all my colleagues in the Implementation and Learning research platform at Linköping University for many interesting discussions on the topic of implementation. I am grateful for the many learning opportunities that this platform has provided. Linköping University provides creative and learning environment if you are serious about conducting re- 
search on implementation issues. And a special thanks to Carina Berterö for valuable courses in qualitative method.

"Learn from yesterday, live for today, hope for tomorrow. The important thing is to not stop questioning". - Albert Einstein

From my first day at the department, Kajsa Bendtsen has been taking care of me. Thank you for always helping me out! Kajsa also put me in the room with my doctoral colleagues Kristin Thomas and Janna Skagerström and am I thankful for that! Kristin and Janna you are a source of comfort and laughter and I am so grateful that you have become my close friends.

After a year on my doctoral journey I was recruited as a manager for the research and development unit in the County Council of Östergötland. I truly had little idea what I was supposed to do in that position but Tommy Skau and Nina Nelson believed that I was suitable. And who am I to question them! Thank you for believing in me, this position with all the challenges it brings, has really made me grow as a person and extended my knowledge. I am really passionate about the task to improve health care through implementation of new knowledge and figure out how we best can structure the organization so we can provide the best health care for our citizens. Nina, thank you for sharing your knowledge with me and your guidance into the world of health care; it has been challenging but most of all fun. Thank you too for all the laughter and your friendship. I will always carry our time at Harvard as a special memory.

We cannot solve our problems with the same thinking we used when we created them. - Albert Einstein

All I knew about being a manager was what I had read in the literature. Luckily, all my colleagues in the unit for research and development are patient and they have taught me both how to become a leader but also about research and development in our County Council. Sorry for using the term colleagues, we are more than that! We are a team - actually the best team ever! Also thank you for your understanding and support, so that I have been able to balance both my occupations all these years. Thank you, Lena Lindgren, Yvonne Jonsson (thank you for reference work), Ebba Berglund, Anna-Lena Nylander, Veronica Fäldt, Ulf Dahlqvist (for all IT support, among other things), and Göran Atterfors. And my current manager Jan Marcusson, your support especially in 
this last phase of writing the thesis has been so valuable. You have given me all the time I needed to focus on my research, never doubting that I would not be able to perform in my manager position at the same time; thank you for your trust. To Åsa Källstrand Thor, thank you for making fantastic posters to present on conferences and the beautiful design of my thesis cover, you are the best! The work environment in the County Council of Östergötland has been perfect for combining both my positions. I have had the great pleasure to get funding for two research visits that have increased my knowledge in several ways and hopefully I have passed that knowledge on in the organization.

ALL MY FRIENDS! Who am I without you? You are a constant source of love and joy and I cannot with words express my gratitude and love that I feel for you! To my close crew thank you (you are mentioned in no special order) Sandra Berglund, Anna Rosengren, Sara Wilhelmsson, Maggan Green, Issa Barrling, Sara Nielsen, Sandra Månsson, Anna Axelsson. You are always by my side; with that friendship around me I am never afraid of failure because I know you always be there no matter what. To Jimpa for your caring all these years we have known each other; you have always been there supporting me and I hope I have been there for you as well. Further, for uncountable training sessions and for introducing me to swim-run this year. We rocked at $X$-terra!

To my family, from the bottom of my heart thank you! My mother and Janne, I can always count on you for better and for worse. Mother, throughout my life you have always believed in me. And no matter what crazy idea I have had or fulfilled, you have always been proud of me. I hope you are proud of me now as a person and over my accomplishments. Topsi (Matias), I know that some people find it strange I still 17 years after break-up have such a close relationship with my daughter's father, I find this natural. Since I was 16 years old you have been watching my back, comforting me when needed, encouraging me, and telling me when I doubted that everything will be ok, thank you. Jonas, when we first met I had been studying at the University for a year; you told me that "you should become a PhD student;" apparently you liked my mind. At that time I didn't even know what that was. You were right; here I am, a Medicine Doctor to be. I hope you know how thankful I am for your encouragement and love throughout the years.

And above all, to my love and driving force, my daughter Saga, thank you. I was 17 when you came into my young world. And I promised you and myself that even if I, at that time, had nothing, not even a high school education, our 
life should include anything we needed. Today, you are studying Sociology at the University and you truly are my pride and joy.

I understand that all that is written above creates a picture of living in a dream or at least a very loveable environment; this is, however, true. I am this fortunate.

Linköping 2015-09-29

Petra Dannapfel 


\section{SVENSK SAMMANFATTNING}

Forskningens framsteg skapar gynnsamma förutsättningar för förbättrad diagnostisk och behandling inom fysioterapi och andra områden inom hälso- och sjukvården. Framväxten av evidensbaserad praktik (EBP) har lett till ökade förväntningar på en vetenskaplig kunskapsbas i många verksamheter. EBP innebär en integration av bästa tillgängliga forskningsresultat med klinisk erfarenhet och patientens värderingar och prioriteringar. Samtidigt har implementeringsforskning identifierat många individuella och kontextuella hinder för att nyttiggöra forskning inom fysioterapi och andra områden inom hälsooch sjukvården. Strategier för att underlätta en mer EBP har ofta fokuserat på individer, för att påverka deras kunskap, förmågor och attityder beträffande forskningsanvändning. Det finns dock en växande insikt om betydelsen av kontextuella förhållanden som t.ex. ledarskap och kultur för att åstadkomma en ökad användning av forskningsbaserad kunskap i klinisk praxis.

Denna avhandling har genomförts mot bakgrund av ett ökat intresse för EBP inom fysioterapi. Syftet har varit att utforska vilka förutsättningar som föreligger på olika nivåer, individ och kontext (arbetsplats, organisation och samhällsnivå), för fysioterapeuters forskningsanvändning i klinisk praxis och implementering av EBP inom fysioterapi. Avhandlingen baseras på fyra studier som har genomförts i flera olika fysioterapeutiska verksamheter i olika landsting/regioner i Sverige. Data insamlades under perioden 2011-2014 genom individuella och fokusgruppintervjuer. Data har analyserats med flera olika kvalitativa analysansatser.

Resultaten visar att fysioterapeuter skiftar med avseende på sin motivation att använda forskning i klinisk praxis, från ointresse för forskningsanvändning till hög grad av motivation. De flesta fysioterapeuter beskriver forskningsanvändning i positiva termer och är motiverade att använda forskning i sitt vardagliga arbete. Fysioterapeuters medverkan i ett forskningsprojekt ledde till ett individuellt lärande kring forskning som kan bidra till en mer forskningsinfluerad praktik inom fysioterapi. Det organisatoriska lärandet var däremot begränsat. Flera faktorer på olika nivåer (individ, arbetsplats och samhällsnivå) stödjer fysioterapeuters användning av forskning i sin kliniska praxis. Samtidigt framkommer att chefer inom fysioterapi i mer begränsad utsträckning bidrar till att skapa en kultur som främjar implementering av EBP inom 
fysioterapi. Istället tycks forskningsrelaterade frågor till stor del vara beroende av engagerade enskilda fysioterapeuter som håller sig à jour med aktuell forskning och informerar sina kollegor om de senaste forskningsrönen. 


\section{REFERENCES}

Aarons GA, Ehrhart MG, Farahnak LR, Sklar M. 2014a. Aligning leadership across systems and organizations to develop a strategic climate for evidencebased practice implementation. Annu Rev Public Health 35:255-274.

Aarons GA, Ehrhart MG, Farahnak. LR 2014b. The implementation leadership scale (ILS): development of a brief measure of unit level implementation leadership. Implement Sci 9:45.

Aarons GA. 2006. Transformational and transactional leadership: association with attitudes toward evidence-based practice. Psychiatr Serv 57:1162-1169.

Aiken LH, Sochalski J, Lake ET. 1997. Studying outcomes of organizational change in health services. Med Care 35:NS6-18.

Ajzen I. 1991. The theory of planned behaviour. Organ Behav Hum Decis Process 50:179-211.

Ajzen I, Fishbein M. 1980. Understanding attitudes and predicting social behavior. Englewood Cliffs, NJ: Prentice Hall.

Akinbo SRA, Odebiyi DO, Okunola TE, Aderoba OT. 2009. Evidence-based practice: knowledge, attitudes and beliefs of physiotherapists in Nigeria. Internet J Med Informatics 4:169-172.

Argyris C. 1976. Increasing leadership effectiveness. New York: WileyInterscience.

Argyris C, Schon DA. 1974. Theory in practice: increasing professional effectiveness. San Francisco, CA: Jossey-Bass. 
Ashton CM, Khan MM, Johnson ML, Walder A, Stanberry E, Beyth RJ, et al. 2007. A quasi-experimental test of an intervention to increase the use of thiazide based treatment regimens for people with hypertension. Implement Sci 2:5.

Aveyard H, Sharp P. 2013. A beginner's guide to evidence-based practice in health and social care. Maidenhead, UK: Open University Press.

Avolio BJ, Zhu WC, Koh W, Bhatia P. 2004. Transformational leadership and organizational commitment: mediating role of psychological empowerment and moderating role of structural distance. J Organ Behav 25:951-968.

Bandura A. 1977. Social learning theory. Englewood Cliffs, NJ: Prentice Hall.

Bandura A. 1986. Social foundations of thought and action: a social-cognitive theory. Englewood Cliffs, NJ: Prentice Hall.

Bandura A. 1997. Self-efficacy: the exercise of control New York: WH Freeman.

Bang H. 2009. Organisationskultur. Malmö: Studentlitteratur.

Barnard S, Wiles R. 2001. Evidence-based physiotherapy: physiotherapists' attitudes and experiences in the Wessex area. Phys Ther 87:115-124.

Bass BM. 1985. Leadership and performance beyond expectations. New York: Free Press.

Bass BM, Avolio BJ. 1997. Full range of leadership development: manual for the Multifactor Leadership Questionnaire. Palo Alto, CA: Mind Garden.

Battilana J, Gilmartin M, Sengul M, Pache A-C, Alexander JA. 2010. Leadership competencies for implementing planned organizational change. Leadersh Q 21:422-438. 
Bekkering GE, Engers AJ, Wensing M, Hendriks HJM, van Tulder MW, Oostendorp RAB, et al. 2003. Development of an implementation strategy for physiotherapy guidelines on low back pain. Aust J Physiother 49:208-213.

Bridges PH, Bierema LL, Valentine T. 2007. The propensity to adopt evidencebased practice among physical therapists. BMC Health Serv Res 7:103.

Broberg C, Tyni-Lenné R. 2009. Sjukgymnastik som vetenskap och profession. Legitimerade Sjukgymnasters Riksförbund.

Brownson RC, Colditz GA, Proctor EK. 2012. Dissemination and implementation research in health. New York: Oxford University Press.

Bryman A. 2001. Samhällsvetenskapliga metoder. Liber.

Bycio P, Hackett RD, Allen JS. 1995. Further assessment of Bass's 1985 conceptualization of transactional and transformational leadership. J Appl Psychol 80:468-478.

Cabrera E, Cabrera A. 2005. Fostering knowledge sharing through people management practices. Int J Human Resource Manage 16/5:720735.

Caldwell K, Coleman K, Copp G, Bell L, Ghazi F. 2007. Preparing for professional practice: how well does professional training equip health and social care practitioners to engage in evidence-based practice. Nurs Educ Today 27:518-528.

Cappelli P, Sherer PD. 1991. The missing role of context in OB: the need for a meso-level approach. Res Organ Behav 13:55-110.

Clarke N, Higgs MJ, Meyer E. 2011. A study of culture change. London: Chartered Institute of Personnel and Development.

Conner M, Norman P. 2005. Predicting health behaviour: a social cognition approach. In: Conner M, Norman P, editors. Predicting health behaviour (pp. 1-27). Maidenhead, Berkshire: Open University Press. . 
Cooper WH, Withey MJ. 2009. The strong situation hypothesis. Pers Soc Psychol Rev 13:62-72.

Cummings GG, Estabrooks CA, Midodzi LWK, Wallin L, Hayduk L. 2007. Influence of organizational characteristics and context on research utilization. Nurs Res 56:25-39.

Damanpour F, Schneider M. 2006. Phases of the adoption of innovation in organizations: effects of environment, organization and top managers. Br J Manag 17:215-236.

Damschroder LJ, Aron DC, Keith RE, Kirsh SR, Alexander JA, Lowery JC. 2009. Fostering implementation of health services research findings into practice: a consolidated framework for advancing implementation science. Implement Sci 4:50.

Dannapfel P, Peolsson A, Nilsen P. 2013. What supports physiotherapists' use of research in clinical practice? A qualitative study. Implement Sci 8:31.

Dawes M, Summerskill W, Glasziou P, Cartabellotta A, Martin J, Hopayian K, et al.; Second International Conference of Evidence-Based Health Care Teachers and Developers. 2005. Sicily statement on evidence-based practice. BMC Med Educ 5:1.

Deci EL, Ryan RM. 1985. Intrinsic motivation and self-determination in human behavior. New York, Plenum.

Denison DR. 1990. Corporate culture and organizational effectiveness. New York: Wiley.

Dixon N. 1997. The hallways of learning. Organ Dyn 25:23-24.

Dopson S, Fitzgerald L. 2005. The active role of context. In: Dopson S, Fitzgerald L, editors. Knowledge to action? Evidence-based health care in context (pp. 79-103). Oxford: Oxford University Press. 
Dunnant S, Porter R. 1996. The age of anxiety. London: Virago Press.

Durlak JA, DuPre EP. 2008. Implementation matters: a review of research on the influence of implementation on program outcomes and the factors affecting implementation. Am J Community Psychol 41:327-350.

Easterby-Smith M, Lyles MA. 2011. The evolving field of organizational learning and knowledge management. In: Easterby-Smith M, Lyles MA, editors. Handbook of organizational learning and knowledge management (pp. 1-22). Chichester: John Wiley.

Eccles MP, Mittman BS. 2006. Welcome to Implementation Science. Implement Sci 1:1.

Ellström PE. 1992. Kompetens, utbildning och lärande i arbetslivet: problem, begrepp och teoretiska perspektiv 1992. Stockholm : Publica.

Ellström PE. 2010. Practice-based innovation: a learning perspective. J Workplace Learn 22:27-40.

Estabrooks CA. 1999. The conceptual structure of research utilization. Res Nurs Health 22:203-216.

Estabrooks CA, Thompson DS, Lovely JJ, Hofmeyer A. 2006. A guide to knowledge translation theory. J Contin Educ Health Prof 26:25-36.

Evidence-Based Medicine Working Group. 1992. Evidence-based medicine: a new approach to teaching the practice of medicine. JAMA 268:2420-2425.

Ferlie E, Shortell SM. 2001. Improving the quality of health care in the United Kingdom and the United States: a framework for change. Milbank Q 79:281315.

Filbay SR, Hayes K, Holland AE 2012. Physiotherapy for patients following coronary artery bypass graft (CABG) surgery: limited uptake of evidence into practice. Physiother Theory Pract 28:178-187. 
Fishbein M, Ajzen I. 1975. Belief, attitude, intention, and behavior: an introduction to theory and research. Reading, MA: Addison-Wesley.

Fixsen DL, Naoom SF, Blasé KA, Friedman RM, Wallace F. 2005. Implementation research :a synthesis of the literature. Tampa, FL: University of South Florida, Louis de la Parte Florida Mental Health Institute, The National Implementation Research Network.

Fritz JM, Cleland JA, Brennan GP. 2007. Does adherence to the guideline recommendation for active treatments improve the quality of care for patients with acute low back pain delivered by physical therapists? Med Care 45:973980.

Fruth SJ, van Veld RD, Despos CA, Martin RD, Hecker A, Sincroft EE. 2010. The influence of a topic-specific research-based presentation on therapists' beliefs and practices regarding evidence-based practice. Physiother Theory Pract 26: 537-557.

Funk SG, Champagne MT, Tornquist EM. 1995. Barriers and facilitators of research utilization. Nurs Clin North Am 3:30.

Gadamer HG. 2004. Truth and method. London: Continuum.

Gagliardi P. 1986. The creation and change of organizational cultures: a conceptual framework. Organ Stud 7:117-134.

Giddens A. 1993. Sociology. Lund: Studentlitteratur.

Gifford WA, Davies B. 2008. Doing the right things to do things right: a commentary on leadership and the use of evidence in practice. Worldviews Evid Based Nurs 5:170-171.

Gill R, editor. Theory and practice of leadership. 2nd ed. London: Sage Publications; 2011. 
Ginsburg L, Tregunno D. 2005. New approaches to interprofessional education and collaborative practice:lessons from organizational change literature. J. Interprof Care, May:19

Greenhalgh T, Robert G, Macfarlane F, Bate P, Kyriakidou O. 2004. Diffusion of innovations in service organizations: systematic review and recommendations Milbank Q 82:581-629.

Greenhalgh T, Robert G, Macfarlane F, Bate P, Kyriakidou O, Peacock R. 2005. Storylines of research in diffusion of innovation: a meta-narrative approach to systematic review. Soc Sci Med 61:417-430.

Grimmer-Somers K, Lekkas P, Young A, Kumar S. 2007. Perspectives on research evidence and clinical practice: a survey of Australian physiotherapists. Physiother Res Int 12:147-161.

Grimshaw JM, Greener J, Ibbotson T, Maclennan G, Ibbotson T, Kahan JP, et al. 2006. Is the involvement of opinion leaders in the implementation of research findings a feasible strategy? Implement Sci 1:3.

Grol R, Wensing M, Hulcher M, Eccles M. 2004. Theories on implementation of change in healthcare. In: Grol R, Wensing M, Eccles M, editors. Improving patient care - the implementation of change in clinical practice. London: Elsevier.

Guba EG, Lincoln YS. 1994. Competing paradigms in qualitative research. In: Denzin NK, Lincoln YS, editors. Handbook of qualitative research (pp. 105117). London: Sage.

Gumusluoglu L, Ilsev A. 2009. Transformational leadership, creativity and organizational innovation. J Bus Res 62:461-473.

Gurses AP, Marsteller JA, Ozok AA, Xiao Y, Owens S, Pronovost PJ. 1020. Using an interdisciplinary approach to identify factors that affect clinicians' compliance with evidence-based guidelines. Crit Care Med 38(8 Suppl):S282-291. 
Hallencruetz J. 2012. Under the skin of change meanings, models and management. Doctoral Thesis. Luleå University of Technology.

Hannes K, Staes F, Goedhuys J, Aertgeerts B. 2009. Obstacles to the implementation of evidence-based physiotherapy in practice: a focus group-based study in Belgium (Flanders). Physiother Theory Pract 25:476-488.

Haynes RB, Devereaux PJ, Guyatt GH. 2002. Physichians' and patients choices in evidence based practice. BMJ Jun 8:324(7350):1350

Heiwe S, Nilsson Kajermo K, Tyni-Lenné R, Guidetti S, Samuelsson M, Andersson I-L, et al. 2011. Evidence-based practice: attitudes, knowledge and behaviour among allied health care professionals. Int J Qual Health Care 23:198209.

Herscovitch L, Meyer JP. 2002. Commitment to organizational change: extension of a three-component model. J Appl Psychol 87:474-487.

Hill N, Seo. M, Kang. J, Taylor M. 2012. Building employee commitment to change across organizational levels: the influence of hierarchal distance and direct managers' transformational leadership. Organ Sci 23:758-777.

Holmes BJ, Finegood DT, Riley BL, Best A. 2012. Systems thinking in dissemination and implementation research. In: Brownson RC, Colditz GA, Proctor EK, editors. Dissemination and implementation research in health (pp. 192212). New York: Oxford University Press.

Howell JM, Avolio BJ. 1993. Transformational leadership, transactional leadership, locus of control and support for innovation: key predictors of consolidated-business-unit per-performance. J Appl Psychol 78:891-902.

Hsieh HF, Shannon SE. 2005. Three approaches to qualitative content analysis. Qual Health Res 15:1277-1288.

Iles R, Davidson M. 2006. Evidence based practice: a survey of physiotherapists' current practice. Physiother Res Int 11:93-103. 
Jarvis P, Holford J, Griffin C. 2003. The theory and practice of learning. Abingdon: Routledge.

Jassawalla AR, Sashittal HC. 2002. Cultures that support product innovation processes. Acad Manage Exec 16, 42-54.

Jette DU, Bacon K, Batty C, Carlson M, Ferland A, Hemingway RD, et al. 2003. Evidence-based practice: beliefs, attitudes, knowledge, and behavior of physical therapists. Phys Ther 83:786-805.

Johnson P, Duberley J. 2000. Understanding management research. London: Sage.

John-Steiner V, Mahn H. 1996. Sociocultural approaches to learning and development: a Vygotskian framework. Educ Psychol 31:191-206.

Jull G, Moore A. 2013. Physiotherapy's identity. Man Ther 18:447-448.

Jung Di, Chow C, Wu A. 2003. The role of transformational leadership in enhancing organizational innovation: hypotheses and som preliminary findings. Leadersh Q 14:525-544.

Kajermo KN, Undén M, Gardulf A, Eriksson LE, Orton ML, Arnetz BB, et al. 2008. Predictors of nurses' perceptions of barriers to research utilization. J Nurs Manage 16:305-314.

Kamwendo K. 2002. What do Swedish physiotherapists feel about research? A survey of perceptions, attitudes, intentions and engagement. Physiother Res Int 7:23-34.

Kim DH. 1993. Transformational leadership. The leader with the "beginner's mind. Healthc Forum J 36:32-37.

Kitson A, Powell K, Hoon E, Newbury J, Wilson A, Beilby J. 2013. Knowledge translation within a population health study: how do you do it. Implement Sci $8: 54$. 
Kotter JP. 1990. What leaders really do. Harv Bus Rev 68:103-111.

Krippendorff K. 2004 Content analysis. An introduction to its methodology. Thousand Oaks, CA: Sage.

Latta G. 2009. A process model of organizational change in cultural context (OC3Model) - the impact of organizational culture on leading change. J Leadersh Organ Stud 16(3):19-37.

Lincoln YS, Guba E. 1985. Naturalistic Inquiry Newbury Park, CA: Sage Publications.

Logan J, Graham I. 1998. Toward a comprehensive interdisciplinary model of health care research use. Sci Commun 20:227-246.

Ludewig PM, Lawrence RL, Braman JP. 2013. What's in a name? Using movement system diagnoses versus pathoanatomic diagnoses. J Orthop Sports Phys Ther 43:280-283.

Marchionni C, Ritchie J. 2008. Organizatonal factors that support the implementation of a nursing Best Practice Guideline. J Nurs Manage 16:266-274.

McCormack B, Kitson A, Harvey G, Rycroft-Malone J, Titchen A, Seers K. 2002. Getting evidence into practice: the meaning of "context". J Adv Nurs 38:94-104.

Menon A, Korner-Bitensky N, Kastner M, McKibbon KA, Straus S. 2009. Strategies for rehabilitation professionals to move evidence-based knowledge into practice: a systematic review. J Rehabil Med 41:1024-1032.

Mikhail C, Korner-Bitensky N, Rossignol M, Dumas JP. 2005. Physical therapists' use of interventions with high evidence of effectiveness in the management of a hypothetical typical patient with acute low back pain. Phys Ther 85:1151-1167. 
Mischel W. 1977. The interaction of person and situation. In: Magnusson D, Endler NS, editors. Personality at the crossroads: current issues in interactional psychology (pp. 333-352). Hillsdale, NJ: Lawrence Erlbaum.

Mitchell L, Fife S, Chochia AA, Leong D, Dixon S 3rd, Airola A, et al. 1996. Three teams: improving thrombolytic therapy. Jt Comm J Qual Improve 22:379-390.

Mittman B. 2012. Implementation science in health care. In Brownson RC, Colditz GA, Proctor EK, editor. Dissemination and implementation research in health (pp. 400-418). Oxford: Oxford University Press.

Mohr DC, VanDeusen LC, Meterko M. 2008. Predicting healthcare employees' participation in an office redesign program: attitudes, norms and behavioural control. Implement Sci 3:47.

Mooradian T, Renzl B, Matzler K. 2006. Who trusts? Personality trust and knowledge sharing. Manage Learn 37:523-540.

Moser L, DeLuca N, Bond G, Rollins A. 2004. Implementing evidence-based psychosocial practices: lessons learned from statewide implementation of two practices. Int J Neuropsychiatr Med 9:926-936.

Mowday RT, Sutton RI. 1993. Organizational behavior: linking individuals and groups to organizational contexts. Annu Rev Psychol 44:195-229.

Nilsagård Y, Lohse G. 2010. Evidence-based physiotherapy: a survey of knowledge, behaviour, attitudes and prerequisites. Adv Physiother 12:179186.

Nilsen P. 2015. Making sense of implementation theories, models and frameworks Implement Sci 10:53.

Nilsen P, Roback K, Brostrom A, Ellström PE. 2012. Creatures of habit: accounting for the role of habit in implementation research on clinical behaviour change. Implement Sci 7:53. 
Nilsen P, Ståhl C, Roback K, Cairney P. 2013. Never the twain shall meet? A comparison of implementation science and policy implementation research. Implement Sci 8:63.

Nutley SM, Walter I, Davies HTO. 2007. Using evidence: how research can inform public services. Bristol: The Policy Press.

Ogbonna E, Harris LC. 2000. Leadership style, organizational culture and performance: empirical evidence from UK companies. Int J Hum Resource Manage 11:766-788.

Olsson TM. 2007. Reconstructing evidence-based practice: an investigation of three conceptualisations of EBP. Evid Policy 3:271-285.

Ostroff C, Kinicki AJ, Tamkins MM. 2003. Organizational culture and climate. In: Borman DR, Ilgen R, Klimoski J, editors. 2012. Handbook of psychology: Volume 12: Industrial and organizational psychology (pp. 565-594). Hoboken, NJ: John Wiley.

Oswick C, Anthony P, Keenoy T, Mangham IL. 2000. A dialogic analysis of organizational learning. J Manag Stud 37:887-901.

Ottosson A. 2013. Sjukgymnastyrket 200 år. En essä om en mångbottnad forskningsresa. Fysioterapi 6:40-45.

Ottosson A. 2005. Sjukgymnasten - vart tog 'han' vägen? En undersökning av sjukgymnastyrkets maskulinisering och avmaskulinisering 1813-1934. Göteborg.

Overmeer T, Linton SJ, Boersma K. 2004. Do physical therapists recognize established risk factors? Swedish physical therapists' evaluation in comparison to guidelines. Physiotherapy 90:35-41.

Palfreyman S, Tod A, Doyle J. 2003. Comparing evidence-based practice of nurses and physiotherapists. Br J Nurs 12:246-253. 
Patton MQ. 2002. Qualitative research and evaluation methods. Thousand Oaks, CA: Sage.

Pettigrew A, Ferlie E, McKee L. 1992. Shaping strategic change. London: Sage.

Phillips DC, Soltis JF. 2009. Perspectives on learning. New York: Teachers College Press.

Podsakoff PM, MacKenzie SB, Bommer WH. 1996. Transformational leader behaviours and substitutes for leadership as determinants of employee satisfaction, commitment, trust, and organizational citizenship behaviours. J Manag 22:259-298.

Prather CW, Thurell MC. 2002. Involve everyone in the innovation process. Res Technol Manage 45:13-16.

Pressman JL, Wildavsky AB; Oakland Project. 1973. Implementation: how great expectations in Washington are dashed in Oakland: Or, Why it's amazing that Federal programs work at all, this being a saga of the Economic Development Administration as told by two sympathetic observers who seek to build morals on a foundation of ruined hopes. Berkeley, CA: University of California Press.

Quinn JB. 1992. Intelligent enterprise. New York: Free Press.

Reichenpfader U, Carlfjord S, Nilsen P. 2015. Leadership in evidence-based practice: a systematic review. Leadersh Health Serv. 28: in press.

Rogers EM. 1993. Diffusion of innovations. 5th ed. New York: Free Press.

Rubin RS, Munz DC, Bommer WH. 2005. Leading from within: the effects of emotion recognition and personality on transformational leadership behavior. Acad Manage J 48:845-858. 
Rutten GM, Degen S, Hendriks EJ, Braspenning JC, Harting J, Oostendorp RA. 2010. Adherence to clinical practice guidelines for low back pain in physical therapy: do patients benefit? Phys Ther 90:1111-1122.

Ryan RM, Deci EL. 2000. Self-determination theory and the facilitation of intrinsic motivation, social development, and well-being. Am Psychol 55:68-78.

Rycroft-Malone J. 2008. Evidence-informed practice: from individual to context. J Nurs Manage 16:404-408.

Rycroft-Malone J. 2010. Promoting Action on Research Implementation in Health Services (PARIHS). In: Rycroft-Malone J, Bucknall T, editors. Models and frameworks for implementing evidence-based practice: linking evidence to action (pp. 109-136). Oxford: Wiley-Blackwell.

Rycroft-Malone J, Bucknall T. 2010. Using theory and frameworks to facilitate the implementation of evidence into practice. Worldviews Evid-Based Nurs 7:57-58.

Sackett DL, Rosenberg WMC, Muir Gray JA, Haynes RB, Richardson WS. 1996. Evidence based medicine: what it is and what it isn't. BMJ 312:71.

Sackett DL, Straus SE, Richardson WS, Rosenberg W, Haynes RB. 2000. Evidence-based medicine: how to practice and teach EBM. 2nd ed. Edinburgh: Churchill Livingstone.

Salbach N, Jaglal S, Korner-Bitensky N, Rappolt S, Davis D. 2007. Practitioner and organizational barriers to evidence-based practice of physical therapists for people with stroke. Phys Ther 87:1284-1303.

Sandström B, Borglin G, Nilsson R, Willman A. 2011. Promoting the implementation of evidence-based practice: a literature review focusing on the role of nursing leadership. Worldviews Evid Based Nurs 8:212-233. 
Sarros JC, Cooper BK, Santora JC. 2008. Building a climate for innovation through transformational leadership and organizational culture. J Leadersh Organ Stud 15:145-158.

Schein EH. 1993. On dialogue, culture, and organizational learning. Organ Dyn 22:40-51.

Schein EH. 2004. Organizational culture and leadership. 3rd ed. San Francisco, CA: Jossey-Bass.

Schein EH. 2010. Organizational culture and leadership. 4th ed. San Francisco, CA: Jossey-Bass.

Scott SD, Plotnikoff RC, Karunamuni N, Bize R, Rodgers W. 2008. Factors influencing the adoption of an innovation: an examination of the uptake of the Canadian Heart Health Kit (HHK). Implement Sci 3:41.

Searle-Leach L. 2005. Nurse executive transformational leadership and organizational commitment. J Nurs Adm 35:228-237.

Sibbald SL, Wathen CN, Kothari A. 2015. An empirically based model for knowledge management in health care organizations. Health Care Manage Rev, in press.

Soydan H, Palinkas LA. 2014. Evidence-based practice in social work. Abingdon: Routledge.

Squires JE, Estabrooks CA, O'Rourke HM, Gustavsson P, Newburn-Cook CV, Wallin L. 2011. A systematic review of the psychometric properties of selfreport research utilization measures used in healthcare. Implement Sci 6:83.

Stetler CB. 2010. Stetler model. In: Rycroft-Malone J, Bucknall T, editors. Models and frameworks for implementing evidence-based practice: linking evidence to action (pp. 51-82). Oxford: Wiley-Blackwell. 
Stetler CB, Ritchie JA, Rycroft-Malone J, Schultz AA, Charns MP. 2009. Institutionalizing evidence-based practice: an organizational case study using a model of strategic change. Implement Sci 4:78.

Stevens KR. 2013. The impact of evidence-based practice in nursing and the next big ideas. Online J Issues Nurs 18:4.

Stevenson K, Lewis M, Hay E. 2004. Do physiotherapists' attitudes towards evidence-based practice change as a result of an evidence-based educational programme? J Eval Clin Pract 10:207-217.

Stevenson K, Lewis M, Hay E. 2006. Does physiotherapy management of low back pain change as a result of an evidence-based educational programme? J Eval Clin Pract 12:365-375.

Strati P. 2000. Theory and method in organization studies. Paradigms and choices. London: Sage.

Straus S, Tetroe J, Graham ID. 2009. Knowledge translation in health care. Moving from evidence to practice. Chichester: Wiley-Blackwell.

Stross JK. 1996. The educationally influential physician. J Contin Educ Health Prof 16:167-172.

Swinkels RA, van Peppen RP, Wittink H, Custers JW, Beurskens AJ. 2011. Current use and barriers and facilitators for implementation of standardised measures in physical therapy in the Netherlands. BMC Musculoskelet Disord 12:106.

Taylor L, Copeland J. 2006. Changes in physiotherapy research, education and professional development in New Zealand. Phys Ther Rev 11:105.

Thompson D. 1970. The tales of three losers. Time 27 July:64-65. 
Titler MG, Kleiber C, Steelman V, Goode C, Rakel B, Barry-Walker J, et al. 1995. Infusing research into practice to promote quality care. Nurs Res 43:307313.

Triandis HC. 1989. The self and social behavior in differing cultural contexts Psychol Rev 96:506-520.

Trinder L. 2000. A critical appraisal of evidence-based practice. In: Trinder L, Reynolds S, editors. Evidence-based practice - a critical appraisal (pp. 212241). Oxford: Blackwell Publishing.

Van der Wees PJ, Jamtvedt G, Rebbeck T, de Bie RA, Dekker J, Hendriks EJ. 2008. Multifaceted strategies may increase implementation of physiotherapy clinical guidelines: a systematic review. Aust J Physiother 54:233-241.

Verplanken B, Aarts H, van Knippenberg A, Moonen A (1998). Habit versus planned behaviour: A field experiment. British Journal of Social Psychology, Vol. 37: 111-128.

Walumbwa FO, Orwa B, Wang P, Lawler JJ. 2005. Transformational leadership, organizational commitment, and job satisfaction: a comparative study of Kenyan and U.S financial firms. Hum Resour Dev Q 16:235-256.

Watzlawick P, Weakland JH, Fisch R. 1974. Changes: principles of problem formation and problem resolution. New York: Norton.

Weiss CH. 1979. The many meanings of research utilization. Public Adm Rev Sep/Oct:426-431.

Williams BW, Kessler HA, Williams MV. 2015. Relationship among knowledge acquisition, motivation to change, and self-efficacy in CME participants. J Contin Educ Health Prof 35(Suppl 1):S13-21.

Xenikou A, Simosi M. 2006. Organizational culture and transformational leadership as predictors of business unit performance. J Manag Psychol 21: 566579. 
Yammarino FJ, Spangler WD, Bass BM. 1993. Transformational leadership and performance: a longitudinal investigation. Leadersh Q 4:81-102.

Yukl G. 2006. Leadership in organizations. 6th ed. Upper Saddle River, NJ: Pearson Education.

\section{Internet sources}

APTA. Policies \& Bylaws: Research. http://www.apta.org/Policies/Research/ (2013)

APTA. Vision Statement for the Physical Therapy Profession and Guiding Principles to Achieve the Vision. http://www.apta.org/Vision/ (2013)

Australian Physiotherapy Council. The Australian Standards for Physiotherapy. http://www.physiocouncil.com.au/standards

National Board of Health and Welfare 2010 http://www.socialstyrelsen. se/Lists/Artikelkatalog/Attachments/18486/2011-11-13.pdf.

LSR. Legitimerade Sjukgymnasters Riksförbund.

http://www.fysioterapeuterna.se/Global/Nyheter_dokument/Synpunkter_utbil dningsdepartementet.pdf

The Swedish School of Sport and Health Sciences. http://www.gih.se/

http://www.socialstyrelsen.se/publikationer2015/2015-9-7 


\section{Papers}

The articles associated with this thesis have been removed for copyright reasons. For more details about these see:

http://urn.kb.se/resolve?urn=urn:nbn:se:liu:diva-122172 